\title{
Synthesis of Eupalinilide E a Promoter of Human Hematopoietic Stem and Progenitor Cell Expansion
}

Trevor C. Johnson, Matthew R. Chin, Tianxu Han, John Paul Shen, Tariq Rana \& Dionicio Siegel

\section{SUPPORTING INFORMATION}

Table of Contents

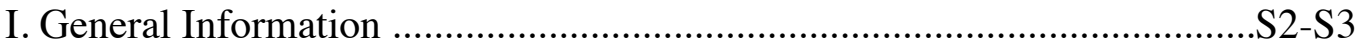

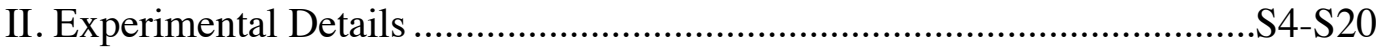

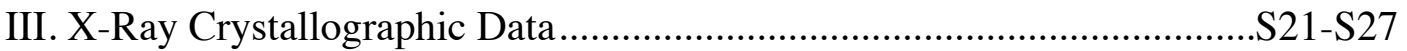

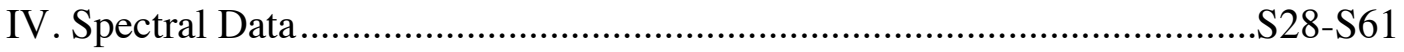

V. Activity of Eupalinilide E Against A549 cells.....................................S62

V1. HSPC Expansion Methods....................................... 63 


\section{General Information}

All reactions were performed in flame dried round bottom or modified Schlenk (Kjedahl shape) flasks fitted with rubber septa under a positive pressure of argon or nitrogen, unless otherwise indicated. Air- and moisture-sensitive liquids and solutions were transferred via syringe or cannula. Organic solutions were concentrated by rotary evaporation at 20 torr in a water bath heated to $40{ }^{\circ} \mathrm{C}$ unless otherwise noted. Diethyl ether $\left(\mathrm{Et}_{2} \mathrm{O}\right)$, methylene chloride $\left(\mathrm{CH}_{2} \mathrm{Cl}_{2}\right)$, tetrahydrofuran (THF) and toluene (PhMe) were purified using a Pure-Solv MD-5 Solvent Purification System (Innovative Technology). Acetonitrile (MeCN) was purified using a Vac 103991 Solvent Purification System (Vacuum Atmospheres). N,N,-Dimethylformamide (DMF) was purchased from Acros (99.8\%, anhydrous), ethanol (EtOH) was purchased from Pharmco-Aaper (200 proof, absolute), and methanol (MeOH) was purchased from Sigma-Aldrich (99.8\%, anhydrous). Where necessary, solvents were deoxygenated by iterative freeze-pump thaw using liquid nitrogen three times. The molarity of $n$-butyllithium was determined by titration against diphenylacetic acid. All other reagents were used directly from the supplier without further purification unless otherwise noted. Analytical thin-layer chromatography (TLC) was carried out using 0.2 mm commercial silica gel plates (silica gel 60, F254, EMD chemical) and visualized using a UV lamp and/or aqueous ceric ammonium molybdate (CAM) or aqueous potassium permanganate (KMnO4) stain, or ethanolic vanillin. Infrared spectra were recorded on a Nicolet 380 FTIR using neat thin film or $\mathrm{KBr}$ pellet technique. High-resolution mass spectra (HRMS) were recorded on a Karatos MS9 and are reported as $\mathrm{m} / \mathrm{z}$ (relative intensity). Accurate masses are reported for the molecular ion $[\mathrm{M}+\mathrm{Na}]^{+},[\mathrm{M}+\mathrm{H}]^{+}$, $[\mathrm{M}]$ or $[\mathrm{M}-\mathrm{H}]^{-}$. Nuclear magnetic resonance spectra $\left({ }^{1} \mathrm{H}-\mathrm{NMR}\right.$ and $\left.{ }^{13} \mathrm{C}-\mathrm{NMR}\right)$ were recorded with a Varian Gemini $\left[\left(400 \mathrm{MHz},{ }^{1} \mathrm{H}\right.\right.$ at $400 \mathrm{MHz},{ }^{13} \mathrm{C}$ at $\left.100 \mathrm{MHz}\right),\left(500 \mathrm{MHz},{ }^{1} \mathrm{H}\right.$ at $500 \mathrm{MHz},{ }^{13} \mathrm{C}$ at $\left.125 \mathrm{MHz}\right),(600$ $\mathrm{MHz},{ }^{1} \mathrm{H}$ at $600 \mathrm{MHz},{ }^{13} \mathrm{C}$ at $150 \mathrm{MHz}$ )]. For $\mathrm{CDCl}_{3}$ solutions the chemical shifts are reported as parts per million (ppm) referenced to residual protium or carbon of the solvent; $\mathrm{CHCl}_{3} \delta \mathrm{H}(7.26 \mathrm{ppm})$ and $\mathrm{CDCl}_{3} \delta$ D $(77.0 \mathrm{ppm})$. For $\left(\mathrm{CD}_{3}\right)_{2} \mathrm{SO}$ solutions the chemical shifts are reported as parts per million (ppm) referenced to residual protium or carbon of the solvents; $\left(\mathrm{CD}_{3}\right)\left(\mathrm{CHD}_{2}\right) \mathrm{SO} \delta \mathrm{H}(2.50 \mathrm{ppm})$ or $\left(\mathrm{CD}_{3}\right)_{2} \mathrm{SO} \delta \mathrm{C}$ (39.5 ppm). For $\left(\mathrm{CD}_{3}\right)_{2} \mathrm{CO}$ solutions the chemical shifts are reported as parts per million (ppm) referenced 
to residual protium or carbon of the solvents; $\left(\mathrm{CD}_{3}\right)\left(\mathrm{CHD}_{2}\right) \mathrm{CO} \delta \mathrm{H}(2.50 \mathrm{ppm})$ or $\left(\mathrm{CD}_{3}\right)_{2} \mathrm{CO} \delta \mathrm{C}(29.8$ ppm). For $\mathrm{C}_{6} \mathrm{D}_{6}$ solutions the chemical shifts are reported as parts per million (ppm) referenced to residual protium or carbon of the solvents; $\mathrm{C}_{6} \mathrm{HD}_{5} \delta \mathrm{H}(7.16 \mathrm{ppm})$ or $\mathrm{C}_{6} \mathrm{D}_{6} \delta \mathrm{C}(128 \mathrm{ppm})$. For $\mathrm{CD}_{3} \mathrm{OD}$ solutions the chemical shifts are reported as parts per million ( $\mathrm{ppm}$ ) referenced to residual protium or carbon of the solvents; $\mathrm{CHD}_{2} \mathrm{OD} \delta \mathrm{H}$ (3.31 ppm) or $\mathrm{CD}_{3} \mathrm{OD} \delta \mathrm{C}(49.0 \mathrm{ppm})$. For $\mathrm{CD}_{2} \mathrm{Cl}_{2}$ solutions the chemical shifts are reported as parts per million (ppm) referenced to residual protium or carbon of the solvents; $\mathrm{CHDCl}_{2} \delta \mathrm{H}$ (5.32 ppm) or $\mathrm{CD}_{2} \mathrm{Cl}_{2} \delta \mathrm{C}$ (53.5 ppm). Coupling constants are reported in Hertz (Hz). Data for ${ }^{1} \mathrm{H}-\mathrm{NMR}$ spectra are reported as follows: chemical shift $(\mathrm{ppm}$, referenced to protium; $\mathrm{s}=$ singlet, $\mathrm{d}=$ doublet, $\mathrm{t}=$ triplet, $\mathrm{q}=$ quartet, $\mathrm{dd}=$ doublet of doublets, $\mathrm{td}=$ triplet of doublets, $\mathrm{ddd}=$ doublet of doublet of doublets, $\mathrm{ddq}=$ doublet of doublet of quartets, $\mathrm{bs}=$ broad singlet, $\mathrm{bd}=$ broad doublet, $\mathrm{m}=$ multiplet, coupling constant $(\mathrm{Hz})$, and integration). Melting points were measured on a MEL-TEMP device without corrections. 


\section{Experimental Details}

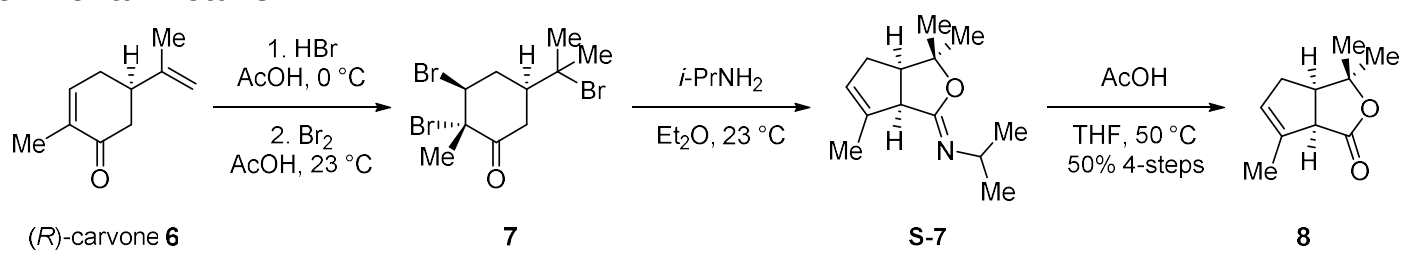

To a stirred solution of $33 \%$ hydrobromic acid in acetic acid $(219 \mathrm{~mL}, 1.33 \mathrm{mmol}, 2.0$ equiv.) at 0 ${ }^{\circ} \mathrm{C}$ was slowly added a solution of $R$-carvone 6 (104 mL, $666 \mathrm{mmol}, 1.0$ equiv.) in acetic acid (100 mL) dropwise over 15 minutes. After 45 minutes, the reaction mixture was poured over ice $\mathrm{H}_{2} \mathrm{O}(600 \mathrm{~mL})$ and extracted with EtOAc $(3 \times 800 \mathrm{~mL})$. The combined organic layers were washed with $\mathrm{H}_{2} \mathrm{O}(800 \mathrm{~mL})$, sat. aq. $\mathrm{NaHCO}_{3}(800 \mathrm{~mL})$ and brine $(800 \mathrm{~mL})$, dried over $\mathrm{Na}_{2} \mathrm{SO}_{4}$, and concentrated in vacuo to give crude monobromide as an amber oil.

To a stirred solution of crude monobromide (154 g, $666 \mathrm{mmol}, 1.0$ equiv.) in $\mathrm{AcOH}(440 \mathrm{~mL}, 1.5$ M) at $23{ }^{\circ} \mathrm{C}$ in a water bath was added a solution of bromine $(41 \mathrm{~mL}, 800 \mathrm{mmol}, 1.2$ equiv. $)$ in $\mathrm{AcOH}(70$ $\mathrm{mL})$ dropwise over 1 hour. After 1.5 hours, the reaction mixture was poured over ice $\mathrm{H}_{2} \mathrm{O}(600 \mathrm{~mL})$ and extracted with $\mathrm{Et}_{2} \mathrm{O}(3 \times 600 \mathrm{~mL})$. The combined organic layers were washed with $\mathrm{H}_{2} \mathrm{O}(600 \mathrm{~mL})$, sat. aq. $\mathrm{NaHCO}_{3}(5 \times 600 \mathrm{~mL})$ and brine $(600 \mathrm{~mL})$, dried over $\mathrm{Na}_{2} \mathrm{SO}_{4}$, and concentrated in vacuo to give crude tribromide 7 as an amber oil.

To a stirred solution of crude tribromide 7 ( $260 \mathrm{~g}, 7.32 \mathrm{~mol}, 1.0$ equiv.) in $\mathrm{Et}_{2} \mathrm{O}(2.66 \mathrm{~L}, 0.25 \mathrm{M})$ at $0{ }^{\circ} \mathrm{C}$ was slowly added isopropyl amine (630 mL, $7.32 \mathrm{~mol}, 11$ equiv.) over 30 minutes. Upon complete addition, the reaction mixture was allowed to warm to $23^{\circ} \mathrm{C}$. After 12 hours, the reaction mixture was cooled to $0{ }^{\circ} \mathrm{C}$ before carefully adding $10 \%$ aq. $\mathrm{H}_{2} \mathrm{SO}_{4}(600 \mathrm{~mL})$. The aqueous layer was separated and the organic layer was extracted with $10 \%$ aq. $\mathrm{H}_{2} \mathrm{SO}_{4}(3 \times 600 \mathrm{~mL})$. The combined aqueous layers were cooled to $0{ }^{\circ} \mathrm{C}$ with stirring before being brought to $\mathrm{pH}=8.0$ with $10 \mathrm{~N} \mathrm{NaOH}(600 \mathrm{~mL})$. The neutralized solution was extracted with EtOAc $(4 \times 600 \mathrm{~mL})$, washed with brine $(600 \mathrm{~mL})$, dried over $\mathrm{Na}_{2} \mathrm{SO}_{4}$, and concentrated in vacuo to give crude imidate as an amber oil.

A stirred solution of crude imidate S-7 (138 g, 666 mol, 1 equiv.) in a 3:1 solution of THF:10\% aq. $\mathrm{AcOH}(1.33 \mathrm{~L}, 0.5 \mathrm{M})$ was heated to $50^{\circ} \mathrm{C}$. After 3 hours, the reaction mixture was cooled to $23^{\circ} \mathrm{C}$ before 
pouring over ice and sat. aq. $\mathrm{NaHCO}_{3}(1 \mathrm{~L})$. The reaction mixture was extracted with EtOAc $(4 \times 600 \mathrm{~mL})$, washed with brine $(600 \mathrm{~mL})$, dried over $\mathrm{Na}_{2} \mathrm{SO}_{4}$, and concentrated in vacuo to give an amber oil. The crude material was purified via silica gel column chromatography (5:1 hexanes:EtOAc) followed by recrystallization from hexanes to give pure bicycle $8(55.3 \mathrm{~g}, 333 \mathrm{mmol}, 50 \%$ over 4 -steps) as a white solid (m.p. $\left.33-35^{\circ} \mathrm{C}\right)$.

$\mathbf{R}_{\boldsymbol{f}}=0.41$ (silica gel, 5:1 hexanes:EtOAc); ${ }^{1} \mathrm{H}-\mathrm{NMR}\left(400 \mathrm{MHz}, \mathrm{CDCl}_{3}\right): \delta 5.23(\mathrm{bd}, J=2.0 \mathrm{~Hz}, 1 \mathrm{H}), 3.39$ $(\mathrm{d}, J=9.0 \mathrm{~Hz}, 1 \mathrm{H}), 2.81,(\mathrm{q}, J=6.3 \mathrm{~Hz}, 1 \mathrm{H}), 2.28(\mathrm{~m}, 2 \mathrm{H}), 1.68(\mathrm{~s}, 3 \mathrm{H}), 1.26(\mathrm{~s}, 3 \mathrm{H}), 1.17(\mathrm{~s}, 3 \mathrm{H}) ;{ }^{13} \mathrm{C}-$ NMR (100 MHz, $\left.\mathrm{CDCl}_{3}\right): \delta 175.2,135.5,126.1,85.2,56.1,47.9,33.1,30.2,23.4,14.1$; IR (film, $\left.\mathrm{cm}^{-1}\right)$ : 1758, 1270, 1119; HRMS (ESI) calc. for $\mathrm{C}_{10} \mathrm{H}_{14} \mathrm{O}_{2}[\mathrm{M}+\mathrm{Na}]^{+}:$189.08860, obs. 189.08940 . 


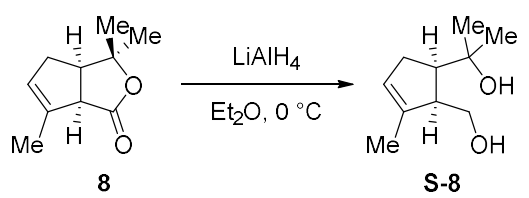

To a stirred solution of bicycle 8 (32 g, $193 \mathrm{mmol}, 1.0$ equiv.) in $\mathrm{Et}_{2} \mathrm{O}(960 \mathrm{~mL}, 0.2 \mathrm{M})$ at $0{ }^{\circ} \mathrm{C}$ was slowly added a $4.0 \mathrm{M}$ solution of lithium aluminum hydride in $\mathrm{Et}_{2} \mathrm{O}(48 \mathrm{~mL}, 193 \mathrm{mmol}, 1.0$ equiv.) over 20 minutes. After 40 minutes, the reaction mixture was carefully quenched with $\mathrm{H}_{2} \mathrm{O}(7.3 \mathrm{~mL}), 15 \%$ aq. $\mathrm{NaOH}(7.3 \mathrm{~mL})$, and $\mathrm{H}_{2} \mathrm{O}(21.9 \mathrm{~mL})$ at $0{ }^{\circ} \mathrm{C}$. The reaction mixture was dried over $\mathrm{Na}_{2} \mathrm{SO}_{4}$ and concentrated in vacuo to give pure diol S-8 $(32.4 \mathrm{~g}, 191 \mathrm{mmol}, 99 \%)$ as a white solid (m.p. $\left.73-75^{\circ} \mathrm{C}\right)$.

$\mathbf{R}_{\boldsymbol{f}}=0.23$ (silica gel, 2:1 hexanes:EtOAc); ${ }^{1} \mathrm{H}-\mathrm{NMR}\left(400 \mathrm{MHz}, \mathrm{CDCl}_{3}\right): \delta 5.43(\mathrm{bs}, 1 \mathrm{H}), 4.57(\mathrm{bs}, 1 \mathrm{H}), 4.36$ (bs, 1H), 3.77 (d, $J=12 \mathrm{~Hz}, 1 \mathrm{H}), 3.51$ (dd, $J=11,5.5 \mathrm{~Hz}, 1 \mathrm{H}), 2.5(\mathrm{bd}, J=2.7 \mathrm{~Hz}, 1 \mathrm{H}), 2.31-2.23$ (m, 2H), 2.09 (bd, J = 8.6 Hz, 1H), $1.65(\mathrm{~s}, 3 \mathrm{H}), 1.33(\mathrm{~s}, 3 \mathrm{H}), 1.20$ (s, 3H); ${ }^{13} \mathrm{C}-\mathrm{NMR}\left(100 \mathrm{MHz}, \mathrm{CDCl}_{3}\right): \delta$ 139.9, 125.8, 71.1, 60.1, 53.6, 51.4, 32.2, 29.8, 29.4, 15.1; IR (film, $\left.\mathrm{cm}^{-1}\right): 3282,1360,1053,1004$; HRMS (ESI): calc. for $\mathrm{C}_{10} \mathrm{H}_{18} \mathrm{O}_{2}[\mathrm{M}+\mathrm{Na}]^{+}:$193.11930, obs. 193.11990. 


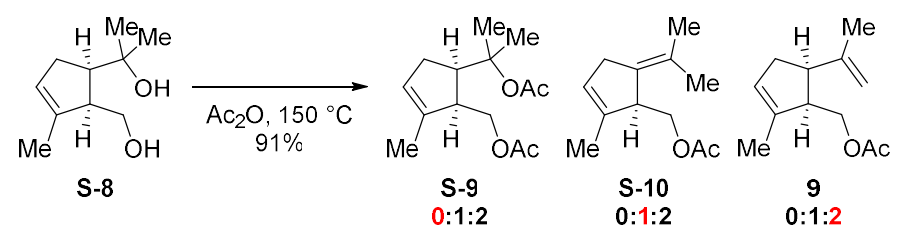

A stirred solution of diol S-8 (40 g, $235 \mathrm{mmol}, 1$ equiv.), activated $4.0 \AA$ molecular sieves $(20 \mathrm{~g}$, $50 \%$ by weight), and $\mathrm{Ac}_{2} \mathrm{O}(160 \mathrm{~mL}, 1.5 \mathrm{M})$ was heated to $150{ }^{\circ} \mathrm{C}$. After 16 hours, the reaction mixture was cooled to $23{ }^{\circ} \mathrm{C}$ and passed through a short silica gel plug (10:1 hexanes:EtOAc) to give an inseparable 2:1 mixture of acetates 9 and S-10 (41.5 g, $214 \mathrm{mmol}, 91 \%)$ as an amber oil.

$\mathbf{R}_{\boldsymbol{f}}=0.46$ (silica gel, 10:1 hexanes:EtOAc); ${ }^{1} \mathrm{H}-\mathrm{NMR}\left(400 \mathrm{MHz}, \mathrm{CDCl}_{3}\right): \delta[\mathbf{S}-10] 5.48$ (bs, $\left.1 \mathrm{H}\right), 4.86$ (s, 1H), 4.80 (s, 1H), 4.07 (dd, $J=11,5.7 \mathrm{~Hz}, 1 \mathrm{H}), 3.83$ (dd, $J=11,5.7 \mathrm{~Hz}, 1 \mathrm{H}), 3.33$ (bs, 1H), 2.88 (bs, 1H), $2.43(\mathrm{td}, J=11,2.0 \mathrm{~Hz}, 1 \mathrm{H}), 2.16(\mathrm{dd}, J=15,7.7 \mathrm{~Hz}, 1 \mathrm{H}), 2.00(\mathrm{~s}, 3 \mathrm{H}), 1.79$ (s, 3H), 1.75 (s, 3H), [9] 5.49 (bs, 1H), $4.25(\mathrm{dd}, J=11,6.6 \mathrm{~Hz}, 1 \mathrm{H}),, 3.97(\mathrm{dd}, J=11,6.6 \mathrm{~Hz}, 1 \mathrm{H}), 2.93(\mathrm{q}, J=8.7 \mathrm{~Hz}, 1 \mathrm{H}), 2.88$ (bs, 1H), 2.73 (q, $J=6.2 \mathrm{~Hz}, 1 \mathrm{H}), 2.03(\mathrm{~s}, 3 \mathrm{H}), 1.77$ (s, 3H), $1.73(\mathrm{~s}, 3 \mathrm{H}), 1.63(\mathrm{~s}, 3 \mathrm{H}) ;{ }^{13} \mathrm{C}-\mathrm{NMR}(100 \mathrm{MHz}$, $\left.\mathrm{CDCl}_{3}\right): \delta 171.0,170.9,144.5,140.4,133.4,126.2,125.4,124.9,110.9,110.9,66.2,63.6,63.6,50.2$, 49.6, 48.5, 36.3, 33.8, 23.1, 21.0, 20.9, 20.5, 16.0, 15.9; IR (film, $\left.\mathrm{cm}^{-1}\right):$ 1741, 1379, 1252, 1038. 


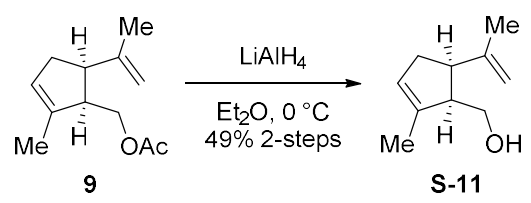

To a stirred solution of acetates 9 and $\mathbf{S}-10\left(41.5 \mathrm{~g}, 214 \mathrm{mmol}, 1.0\right.$ equiv.) in $\mathrm{Et}_{2} \mathrm{O}(1.1 \mathrm{~L}, 0.2 \mathrm{M})$ at $0{ }^{\circ} \mathrm{C}$ was slowly added a $4.0 \mathrm{M}$ solution of lithium aluminum hydride in $\mathrm{Et}_{2} \mathrm{O}(26.7 \mathrm{~mL}, 107 \mathrm{mmol}, 0.5$ equiv.) over 20 minutes. After 40 minutes, the reaction mixture was carefully quenched with $\mathrm{H}_{2} \mathrm{O}(4.1 \mathrm{~mL})$, $15 \%$ aq. $\mathrm{NaOH}(4.1 \mathrm{~mL})$, and $\mathrm{H}_{2} \mathrm{O}(12.3 \mathrm{~mL})$ at $0{ }^{\circ} \mathrm{C}$. The reaction mixture was dried over $\mathrm{Na}_{2} \mathrm{SO}_{4}$ and concentrated in vacuo to give a clear oil. The crude material was purified via silica gel column chromatography (50:1 to 20:1 hexanes:EtOAc) to give pure alcohol S-11 (15.9 g, $105 \mathrm{mmol}, 49 \%$ over 2steps) as a clear oil.

$\mathbf{R}_{\boldsymbol{f}}=0.36$ (silica gel, 5:1 hexanes:EtOAc); ${ }^{1} \mathrm{H}-\mathrm{NMR}\left(400 \mathrm{MHz}, \mathrm{CDCl}_{3}\right): \delta 5.51(\mathrm{~s}, 1 \mathrm{H}), 4.94(\mathrm{~s}, 1 \mathrm{H}), 4.91(\mathrm{~s}$, $1 \mathrm{H}), 3.56(\mathrm{dd}, J=9.4,4.7,2 \mathrm{H}), 2.96(\mathrm{q}, J=8.6 \mathrm{~Hz}, 1 \mathrm{H}), 2.63(\mathrm{bs}, 1 \mathrm{H}), 2.45(\mathrm{dd}, J=12,6.3 \mathrm{~Hz}, 1 \mathrm{H}), 2.17$ (dd, $J=12,6.3 \mathrm{~Hz}, 1 \mathrm{H}), 1.83(\mathrm{~s}, 3 \mathrm{H}), 1.73(\mathrm{~s}, 3 \mathrm{H}), 1.59$ (bs, $1 \mathrm{H}) ;{ }^{13} \mathrm{C}-\mathrm{NMR}\left(100 \mathrm{MHz}, \mathrm{CDCl}_{3}\right): \delta$ 146.4, 139.5, 126.2, 110.8, 61.3, 52.6, 49.3, 34.3, 23.5, 15.5; IR (film, $\mathrm{cm}^{-1}$ ): 3381, 1447, 1037, 888; HRMS (ECCl): calc. for $\mathrm{C}_{10} \mathrm{H}_{16} \mathrm{O}[\mathrm{M}]:$ 152.1201, obs. 152.1196 . 


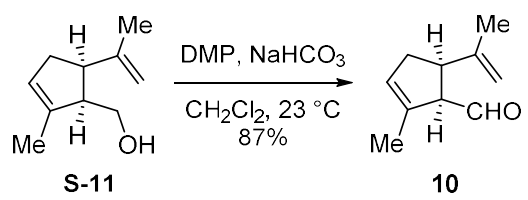

To a stirred solution of alcohol S-11 (26.2 g, $172 \mathrm{mmol}, 1.0$ equiv.) in $\mathrm{CH}_{2} \mathrm{Cl}_{2}(860 \mathrm{~mL}, 0.2 \mathrm{M})$ at $23{ }^{\circ} \mathrm{C}$ was added solid $\mathrm{NaHCO}_{3}(43.4 \mathrm{~g}, 517$ mmol, 3 equiv.), solid Dess-Martin periodinane (110 g, 258 mmol, 1.5 equiv.), and $\mathrm{H}_{2} \mathrm{O}(1 \mathrm{~mL})$. After 45 minutes, the reaction mixture was diluted with sat. aq. $\mathrm{NaHCO}_{3}(500 \mathrm{~mL})$ and sat. $\mathrm{Na}_{2} \mathrm{~S}_{2} \mathrm{O}_{4}$ and stirred for 10 minutes. The reaction mixture was extracted with $\mathrm{CH}_{2} \mathrm{Cl}_{2}(3 \times 800 \mathrm{~mL})$, washed with brine $(800 \mathrm{~mL})$, dried over $\mathrm{Na}_{2} \mathrm{SO}_{4}$, and concentrated in vacuo to give an amber oil. The crude material was purified via silica gel column chromatography (10:1 hexanes:EtOAc) to give pure aldehyde $10(22.5 \mathrm{~g}, 150 \mathrm{mmol}, 87 \%)$ as a clear oil.

$\mathbf{R}_{\boldsymbol{f}}=0.56$ (silica gel, 5:1 hexanes:EtOAc); ${ }^{1} \mathrm{H}-\mathrm{NMR}\left(600 \mathrm{MHz}, \mathrm{CDCl}_{3}\right): \delta 9.35(\mathrm{~d}, J=5.5 \mathrm{~Hz}, 1 \mathrm{H}), 5.77$ (bs, 1H), $4.90(\mathrm{~s}, 1 \mathrm{H}), 4.87(\mathrm{~s}, 1 \mathrm{H}), 3.22(\mathrm{q}, J=9.1 \mathrm{~Hz}, 1 \mathrm{H}), 3.17(\mathrm{t}, J=6.3 \mathrm{~Hz}, 1 \mathrm{H}), 2.71(\mathrm{t}, J=10 \mathrm{~Hz}, 1 \mathrm{H})$, $2.43(\mathrm{dd}, J=16,8.1 \mathrm{~Hz}, 1 \mathrm{H}), 1.75(\mathrm{~s}, 3 \mathrm{H}), 1.67(\mathrm{~s}, 3 \mathrm{H}) ;{ }^{13} \mathrm{C}-\mathrm{NMR}\left(125 \mathrm{MHz}, \mathrm{CDCl}_{3}\right): \delta$ 201.1, 143.2, 135.5, 130.0, 111.7, 63.4, 49.7, 34.6, 22.9, 15.6; IR (film, $\mathrm{cm}^{-1}$ ): 1720, 1446, 892. HRMS (APCI-TOFMS): calc. for $\mathrm{C}_{10} \mathrm{H}_{14} \mathrm{O}[\mathrm{M}+\mathrm{H}]^{+}:$151.1117, obs. 151.1119 . 


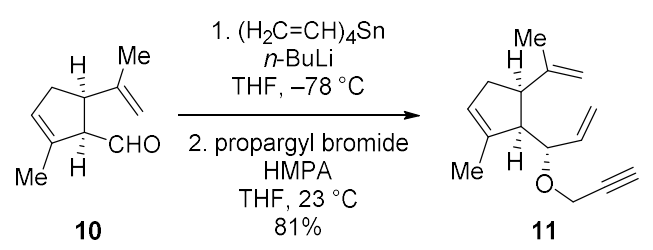

To a stirred solution of tetravinyl tin $(11 \mathrm{~mL}, 59.9 \mathrm{mmol}, 0.4$ equiv. $)$ in THF $(600 \mathrm{~mL})$ at $-78^{\circ} \mathrm{C}$ was added a $2.14 \mathrm{M}$ solution of $n$-butyllithium in hexanes $(91 \mathrm{~mL}, 195 \mathrm{mmol}, 1.3$ equiv.). The reaction mixture was warmed and stirred at $23{ }^{\circ} \mathrm{C}$ for 15 minutes before being cooled back down to $-78{ }^{\circ} \mathrm{C}$ and adding a solution of aldehyde 10 (22.5 g, $150 \mathrm{mmol}, 1$ equiv.) in THF (150 mL). After 15 minutes, freshly distilled neat hexamethylphosphoramide (52 mL, $299 \mathrm{mmol}, 2$ equiv.) was added. After an additional 10 minutes an $80 \%$ solution of propargyl bromide in toluene $(83 \mathrm{~mL}, 749 \mathrm{mmol}, 5$ equiv.) was added. Upon complete addition the reaction mixture was allowed to warm to $23^{\circ} \mathrm{C}$. After 3 hours, the reaction mixture was diluted with sat. aq. $\mathrm{NH}_{4} \mathrm{Cl}(50 \mathrm{~mL})$, extracted with $\mathrm{Et}_{2} \mathrm{O}(3 \times 50 \mathrm{~mL})$, washed with $3.0 \mathrm{~N} \mathrm{LiCl}(3 \times 50$ $\mathrm{mL}$ ), dried over $\mathrm{Na}_{2} \mathrm{SO}_{4}$, and concentrated in vacuo to give a yellow oil. The crude material was purified via silica gel column chromatography (straight hexanes to $50: 1$ to $20: 1$ hexanes:EtOAc) to give pure enyne $11(26.2 \mathrm{~g}, 121 \mathrm{mmol}, 81 \%)$ as a clear oil.

$\mathbf{R}_{\boldsymbol{f}}=0.50$ (silica gel, 2:1 hexanes:EtOAc); ${ }^{1} \mathrm{H}-\mathrm{NMR}\left(400 \mathrm{MHz}, \mathrm{CDCl}_{3}\right): \delta 5.86$ (ddd, $J=17,11,7.4 \mathrm{~Hz}$, 1H), 5.56 (bs, 1H), 5.19 (d, J = $10 \mathrm{~Hz}, 1 \mathrm{H}), 5.15(\mathrm{~d}, J=6.7 \mathrm{~Hz}, 1 \mathrm{H}), 4.90(\mathrm{~s}, 2 \mathrm{H}), 4.10$ (dd, $J=13,2.4 \mathrm{~Hz}$, 1H), $3.93(\mathrm{dd}, J=13,2.4 \mathrm{~Hz}, 1 \mathrm{H}), 3.88(\mathrm{dd}, J=8.6,2.7 \mathrm{~Hz}, 1 \mathrm{H}), 2.88(\mathrm{q}, J=8.2 \mathrm{~Hz}, 1 \mathrm{H}), 2.63(\mathrm{bd}, J=$ $7.8 \mathrm{~Hz}, 1 \mathrm{H}), 2.53$ (ddq, $J=20,9.4,2.4 \mathrm{~Hz}, 1 \mathrm{H}), 2.32$ (t, $J=2.7 \mathrm{~Hz}, 1 \mathrm{H}), 2.12(\mathrm{dd}, J=11,7.4 \mathrm{~Hz}, 1 \mathrm{H})$, 1.80 (s, 3H), 1.79 (s, 3H); ${ }^{13} \mathrm{C}-N M R\left(100 \mathrm{MHz}, \mathrm{CDCl}_{3}\right): \delta 145.3,139.4,137.7,127.4,116.8,111.7,80.7$, 80.4, 73.5, 55.7, 54.9, 51.1, 34.8, 23.5, 17.8; IR (film, $\mathrm{cm}^{-1}$ ): 1384, 1074, 404; HRMS (EC-Cl): calc. for $\mathrm{C}_{15} \mathrm{H}_{20} \mathrm{O}[\mathrm{M}]: 216.1514$, obs. 216.1515 . 


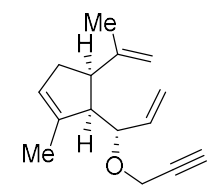

11

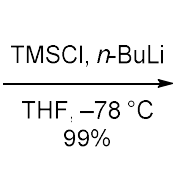

To a stirred solution of enyne $11(26.2 \mathrm{~g}, 121 \mathrm{mmol}, 1.0$ equiv. $)$ in THF $(1.2 \mathrm{~L}, 0.1 \mathrm{M})$ at $-78{ }^{\circ} \mathrm{C}$ was added a $2.14 \mathrm{M}$ solution of $n$-butyllithium in hexanes (68 mL, $145 \mathrm{mmol}, 1.2$ equiv.). After 20 minutes, freshly distilled neat trimethylsilyl chloride $(31 \mathrm{~mL}, 242 \mathrm{mmol}, 2$ equiv.) was added. Upon complete addition the reaction mixture was allowed to warm to $23^{\circ} \mathrm{C}$. After 30 minutes, the reaction mixture was quenched with sat. aq. $\mathrm{NH}_{4} \mathrm{Cl}(400 \mathrm{~mL})$, extracted with $\mathrm{Et}_{2} \mathrm{O}(3 \times 400 \mathrm{~mL})$, washed with brine $(400 \mathrm{~mL})$, dried over $\mathrm{Na}_{2} \mathrm{SO}_{4}$, and concentrated in vacuo to give pure TMS enyne 12 (35 g, $121 \mathrm{mmol}$, $99 \%)$ as a clear oil.

$\mathbf{R}_{\boldsymbol{f}}=0.44$ (silica gel, 20:1 hexanes:EtOAc); ${ }^{1} \mathrm{H}-\mathrm{NMR}\left(400 \mathrm{MHz}, \mathrm{CDCl}_{3}\right): \delta 5.85$ (ddd, $J=17,11,7.4 \mathrm{~Hz}$, 1H), 5.55 (bs, 1H), $5.28(\mathrm{~d}, J=16 \mathrm{~Hz}, 1 \mathrm{H}), 5.14(\mathrm{~d}, J=9.0 \mathrm{~Hz}, 1 \mathrm{H}), 4.88(\mathrm{~s}, 2 \mathrm{H}), 4.11(\mathrm{~d}, J=16 \mathrm{~Hz}, 1 \mathrm{H})$, $3.95(\mathrm{~d}, J=16 \mathrm{~Hz}, 1 \mathrm{H}), 3.94(\mathrm{dd}, J=7.8,2.7 \mathrm{~Hz}, 1 \mathrm{H}), 2.87(\mathrm{q}, J=7.8 \mathrm{~Hz}, 1 \mathrm{H}), 2.63(\mathrm{bd}, J=6.7 \mathrm{~Hz}, 1 \mathrm{H})$, 2.50 (ddq, $J=20,9.4,2.4 \mathrm{~Hz}, 1 \mathrm{H}), 2.13$ (dd, $J=7.8,2.7 \mathrm{~Hz}, 1 \mathrm{H}), 1.81$ (s, 3H), 1.79 (s, 3H), 0.16 (s, 9H); ${ }^{13} \mathrm{C}-\mathrm{NMR}\left(100 \mathrm{MHz}, \mathrm{CDCl}_{3}\right): \delta 145.1,139.6,137.6,127.1,116.8,111.7,102.3,90.3,80.2,56.3,54.8$, 50.9, 34.8, 23.3, 17.7, -0.3; IR (film, $\left.\mathrm{cm}^{-1}\right)$ : 1384, 1251, 1076, 843, 403; HRMS (EC-Cl): calc. for $\mathrm{C}_{18} \mathrm{H}_{28} \mathrm{OSi}[\mathrm{M}]: 288.1909$, obs. 288.1901. 


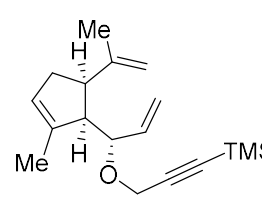

12

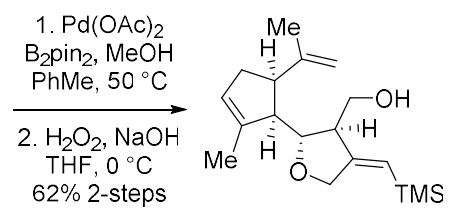

13

To a stirred solution of TMS enyne 12 (20.8 g, $72.1 \mathrm{mmol}, 1.0$ equiv.) in PhMe (720 mL, $0.1 \mathrm{M})$ at $23{ }^{\circ} \mathrm{C}$ was added solid bis(pinacolato)diboron (20.1 g, $79 \mathrm{mmol}, 1.1$ equiv.), palladium(II) acetate (809 $\mathrm{mg}, 3.60 \mathrm{mmol}, 0.05$ equiv.), and $\mathrm{MeOH}(2.92 \mathrm{~mL}, 72.1 \mathrm{mmol}, 1.0$ equiv.). The reaction mixture was heated to and stirred at $50{ }^{\circ} \mathrm{C}$. After 15 hours, the reaction mixture was cooled to $23^{\circ} \mathrm{C}$ and concentrated in vacuo to give the boronate ester as an amber oil.

To a stirred solution of crude boronate ester $(30 \mathrm{~g}, 72.0 \mathrm{mmol}, 1.0$ equiv.) in THF (1.4 L, $0.05 \mathrm{M})$ at $0{ }^{\circ} \mathrm{C}$ was carefully added $3.33 \mathrm{~N} \mathrm{NaOH}(64.9 \mathrm{~mL}, 216 \mathrm{mmol}, 3$ equiv. $)$ and $50 \%$ aq. $\mathrm{H}_{2} \mathrm{O}_{2}(130 \mathrm{~mL}$, $2.16 \mathrm{~mol}, 30$ equiv.) over 1 hour. The reaction mixture was diluted with brine $(700 \mathrm{~mL})$, extracted with EtOAc $(3 \times 500 \mathrm{~mL})$, dried over $\mathrm{Na}_{2} \mathrm{SO}_{4}$, and concentrated in vacuo to give a yellow oil. The crude material was purified via silica gel column chromatography (5:1 hexanes:EtOAc) to give pure alcohol 13 (13.7 g, $44.7 \mathrm{mmol}, 62 \%$ over 2-steps) as a white solid (m.p. $\left.62-64{ }^{\circ} \mathrm{C}\right)$.

$\mathbf{R}_{\boldsymbol{f}}=0.41$ (silica gel, 5:1 hexanes:EtOAc); ${ }^{1} \mathrm{H}-\mathrm{NMR}\left(400 \mathrm{MHz}, \mathrm{CDCl}_{3}\right): \delta 5.54$ (bs, $\left.1 \mathrm{H}\right), 5.50$ (q, $\mathrm{J}=2.4 \mathrm{~Hz}$, 1H), 4.88 (s, 1H), 4.85 (s, 1H), $4.38(\mathrm{dd}, J=14,2.4 \mathrm{~Hz}, 1 \mathrm{H}), 4.23(\mathrm{dt}, J=14,2.4 \mathrm{~Hz}, 1 \mathrm{H}), 3.91$ (t, $J=5.1$ $\mathrm{Hz}, 1 \mathrm{H}), 3.65(\mathrm{dt}, J=11,6.3 \mathrm{~Hz}, 1 \mathrm{H}), 3.60(\mathrm{dt}, J=11,6.3 \mathrm{~Hz}, 1 \mathrm{H}), 2.93(\mathrm{q}, J=7.8 \mathrm{~Hz}, 1 \mathrm{H}), 2.70-2.66$ (bm, 2H), 2.45 (ddq, J = 15, 8.6, $2.4 \mathrm{~Hz}, 1 \mathrm{H}), 2.20$ (dd, $J=14,7.8 \mathrm{~Hz}, 1 \mathrm{H}), 1.81$ (s, 3H), $1.76(\mathrm{~s}, 3 \mathrm{H}), 1.63$ (t, $J=5.9 \mathrm{~Hz}, 1 \mathrm{H}), 0.07$ (s, 9H); ${ }^{13} \mathrm{C}-\mathrm{NMR}\left(100 \mathrm{MHz}, \mathrm{CDCl}_{3}\right): \delta 157.9,145.9,140.3,127.2,119.9,111.9$, 81.2, 70.2, 64.0, 53.5, 51.8, 51.1, 34.7, 22.8, 17.8, -0.7; IR (film, $\left.\mathrm{cm}^{-1}\right): 3404,1384,401$; HRMS (ESI): calc. for $\mathrm{C}_{18} \mathrm{H}_{30} \mathrm{O}_{2} \mathrm{Si}[\mathrm{M}+\mathrm{Na}]^{+}: 329.19070$, obs. 329.19090 . 


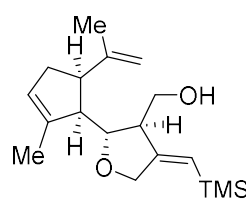

13

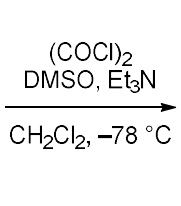

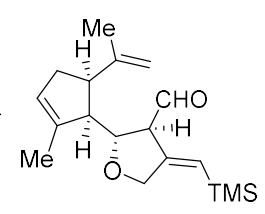

14

To a stirred solution of oxalyl chloride $\left(5.23 \mathrm{~mL}, 59.8 \mathrm{mmol}, 1.5\right.$ equiv.) in $\mathrm{CH}_{2} \mathrm{Cl}_{2}(250 \mathrm{~mL})$ at -78 ${ }^{\circ} \mathrm{C}$ was slowly added a solution of dimethyl sulfoxide (14.2 mL, $199 \mathrm{mmol}, 5$ equiv.) in $\mathrm{CH}_{2} \mathrm{Cl}_{2}(100 \mathrm{~mL})$ over 10 minutes. After 30 minutes, a solution of alcohol 13 (12.2g, $39.9 \mathrm{mmol}, 1$ equiv.) in $\mathrm{CH}_{2} \mathrm{Cl}_{2}(50 \mathrm{~mL})$ was added. After 2 hours, neat triethylamine $(28.0 \mathrm{~mL}, 199 \mathrm{mmol}, 5$ equiv.) was added in a single portion and the reaction mixture was allowed to warm to $23^{\circ} \mathrm{C}$. The reaction mixture was then diluted with $0.1 \mathrm{~N}$ $\mathrm{HCl}(200 \mathrm{~mL})$. The organic layer was separated and washed with $0.1 \mathrm{~N} \mathrm{HCl}(2 \times 200 \mathrm{~mL})$ and $3.0 \mathrm{~N} \mathrm{LiCl}$ $(400 \mathrm{~mL})$, dried over $\mathrm{Na}_{2} \mathrm{SO}_{4}$, and concentrated in vacuo to give crude aldehyde 14 (12.1 g, $39.9 \mathrm{mmol}$, yield taken after subsequent step) as a clear oil.

$\mathbf{R}_{\boldsymbol{f}}=0.69$ (silica gel, 5:1 hexanes:EtOAc); ${ }^{1} \mathrm{H}-\mathrm{NMR}\left(400 \mathrm{MHz}, \mathrm{CDCl}_{3}\right): \delta 9.32(\mathrm{~d}, \mathrm{~J}=3.9 \mathrm{~Hz}, 1 \mathrm{H}), 5.55$ (s, 1H), 5.53 (bs, 1H), $4.85(\mathrm{~s}, 2 \mathrm{H}), 4.41(\mathrm{dd}, J=14,2.4 \mathrm{~Hz}, 1 \mathrm{H}), 4.33(\mathrm{t}, J=6.3 \mathrm{~Hz}, 1 \mathrm{H}), 4.22(\mathrm{dd}, J=14$, $2.4 \mathrm{~Hz}, 1 \mathrm{H}) 3.40(\mathrm{bt}, J=2.4,1 \mathrm{H}), 2.93(\mathrm{q}, J=7.8 \mathrm{~Hz}, 1 \mathrm{H}), 2.71(\mathrm{t}, J=6.3 \mathrm{~Hz}, 1 \mathrm{H}), 2.46$ (dd, $J=15,7.4$ $\mathrm{Hz}, 1 \mathrm{H}), 2.21$ (dd, J = 15, $7.4 \mathrm{~Hz}, 1 \mathrm{H}), 1.82$ (s, 3H), 1.73 (s, 3H), 0.08 (s, 9H); ${ }^{13} \mathrm{C}-\mathrm{NMR}(100 \mathrm{MHz}$ $\left.\mathrm{CDCl}_{3}\right): \delta 196.6,151.9,144.9,139.8,127.4,124.0,112.4,78.7,70.2,63.7,51.7,50.6,34.7,22.9,17.4,-$ 0.9; IR (film, $\mathrm{cm}^{-1}$ ): 1722, 1249, 840; HRMS (ESI): calc. for $\mathrm{C}_{18} \mathrm{H}_{28} \mathrm{O} \mathrm{O}_{2} \mathrm{Si}[\mathrm{M}+\mathrm{Na}]^{+}:$327.17510, obs. 327.17530. 


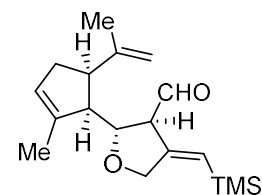

14

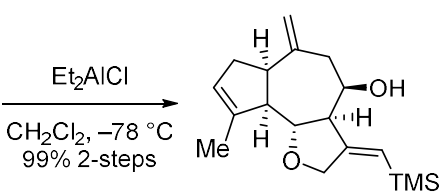

15

To a stirred solution of crude aldehyde 14 (12.1 g, 39.9 mmol, 1.0 equiv.) in $\mathrm{CH}_{2} \mathrm{Cl}_{2}(400 \mathrm{~mL}, 0.1$ M) at $-78{ }^{\circ} \mathrm{C}$ was added a $1.0 \mathrm{M}$ solution of diethylaluminum chloride in hexanes $(19.9 \mathrm{~mL}, 19.9 \mathrm{mmol}$, 0.5 equiv.) in a single portion. After 10 minutes, the reaction mixture was quenched with $10 \%$ aq. $\mathrm{NaOH}$ $(20 \mathrm{~mL})$. The reaction mixture was warmed to $23^{\circ} \mathrm{C}$, further diluted with brine $(200 \mathrm{~mL})$, and the aqueous layer was extracted with $\mathrm{CH}_{2} \mathrm{Cl}_{2}(3 \times 200 \mathrm{~mL})$. The combined organic layers were dried over $\mathrm{Na}_{2} \mathrm{SO}_{4}$ and concentrated in vacuo to give a yellow oil. The crude material was purified via silica gel column chromatography (5:1 hexanes:EtOAc) to give pure 5,7,5-tricycle $15(12.1 \mathrm{~g}, 39.9 \mathrm{mmol}, 99 \%$ over 2steps) as a white solid (m.p. $\left.64-66^{\circ} \mathrm{C}\right)$.

$\mathbf{R}_{\boldsymbol{f}}=0.60$ (silica gel, 5:1 hexanes:EtOAc); ${ }^{1} \mathrm{H}-\mathbf{N M R}\left(400 \mathrm{MHz}, \mathrm{CDCl}_{3}\right): \delta 5.47$ (s, 1H), 5.45 (d, $\mathrm{J}=2.4 \mathrm{~Hz}$ 1H), $4.97(\mathrm{~s}, 1 \mathrm{H}), 4.88(\mathrm{~s}, 1 \mathrm{H}), 4.48(\mathrm{~d}, J=14 \mathrm{~Hz}, 1 \mathrm{H}), 4.22(\mathrm{dt}, J=8.2,4.7 \mathrm{~Hz}, 1 \mathrm{H}), 4.09(\mathrm{dt}, J=14,2.4$ $\mathrm{Hz}, 1 \mathrm{H}), 3.73(\mathrm{t}, J=9.8 \mathrm{~Hz}, 1 \mathrm{H}), 3.16(\mathrm{q}, J=8.0 \mathrm{~Hz}, 1 \mathrm{H}), 2.63(\mathrm{t}, J=9.0 \mathrm{~Hz}, 1 \mathrm{H}), 2.54-2.40(\mathrm{~m}, 5 \mathrm{H}), 1.96$ (d, $J=4.7 \mathrm{~Hz}, 1 \mathrm{H}), 1.84(\mathrm{~s}, 3 \mathrm{H}), 0.10(\mathrm{~s}, 9 \mathrm{H}) ;{ }^{13} \mathrm{C}-\mathrm{NMR}\left(100 \mathrm{MHz}, \mathrm{CDCl}_{3}\right): \delta$ 158.6, 145.2, 142.3, 125.1, 117.3, 115.0, 79.3, 71.1, 66.4, 57.0, 56.1, 49.1, 40.9, 36.8, 17.3, -0.6; IR (film, $\left.\mathrm{cm}^{-1}\right): 3413,1065,838$; HRMS (ESI): calc. for $\mathrm{C}_{18} \mathrm{H}_{28} \mathrm{O}_{2} \mathrm{Si}[\mathrm{M}+\mathrm{Na}]^{+}: 327.17510$, obs. 327.17510 . 


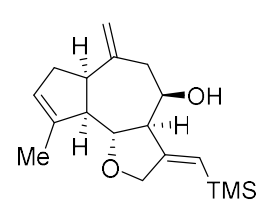

15

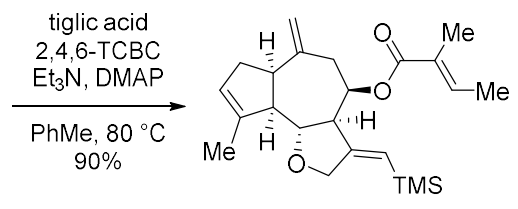

16

To a stirred solution of tiglic acid (13.8 g, $138 \mathrm{mmol}, 2.0$ equiv.) in $\mathrm{PhMe}(345 \mathrm{~mL})$ at $23{ }^{\circ} \mathrm{C}$ was added neat triethylamine (38.4 mL, $276 \mathrm{mmol}, 4.0$ equiv.) and neat 2,4,6-trichlorobenzoyl chloride (23.7 $\mathrm{mL}, 152 \mathrm{mmol}, 2.2$ equiv.). After 1 hour, a solution of 5,7,5-tricycle $15(21.0 \mathrm{~g}, 69.0 \mathrm{mmol}, 1.0$ equiv.) in PhMe (345 mL) and solid dimethylaminopyridine (21.9 g, $179 \mathrm{mmol}, 2.6$ equiv.) were added. The reaction mixture was then heated to $80^{\circ} \mathrm{C}$. After 45 minutes, the reaction mixture was cooled to $23^{\circ} \mathrm{C}$, diluted with sat. aq. $\mathrm{NaHCO}_{3}$, extracted with EtOAc $(3 \times 500 \mathrm{~mL})$, dried over $\mathrm{Na}_{2} \mathrm{SO}_{4}$, and concentrated in vacuo to give an amber oil. The crude material was purified via silica gel column chromatography (20:1 hexanes:EtOAc) to give pure tigloyl ester $16(24.0 \mathrm{~g}, 62.1 \mathrm{mmol}, 90 \%)$ as a clear oil.

$\mathbf{R}_{\boldsymbol{f}}=0.18$ (silica gel, 20:1 hexanes:EtOAc); ${ }^{1} \mathrm{H}-\mathrm{NMR}\left(400 \mathrm{MHz}, \mathrm{CDCl}_{3}\right): \delta 6.75(\mathrm{q}, \mathrm{J}=6.7 \mathrm{~Hz}, 1 \mathrm{H}), 5.49$ (s, 1H), $5.41(\mathrm{q}, J=5.5 \mathrm{~Hz}, 1 \mathrm{H}), 5.31(\mathrm{~s}, 1 \mathrm{H}), 4.91(\mathrm{~s}, 1 \mathrm{H}), 4.77(\mathrm{~s}, 1 \mathrm{H}), 4.47(\mathrm{~d}, J=14 \mathrm{~Hz}, 1 \mathrm{H}), 4.06(\mathrm{~d}, J=$ $14 \mathrm{~Hz}, 1 \mathrm{H}), 3.89$ (t, $J=9.4 \mathrm{~Hz}, 1 \mathrm{H}), 3.16(\mathrm{q}, J=7.8 \mathrm{~Hz}, 1 \mathrm{H}), 2.69(\mathrm{~d}, J=9.0 \mathrm{~Hz}, 1 \mathrm{H}), 2.68(\mathrm{t}, J=9.0 \mathrm{~Hz}$, 1H), 2.60 (dd, $J=14,5.5 \mathrm{~Hz}, 1 \mathrm{H}), 2.47(\mathrm{dd}, J=14,5.1 \mathrm{~Hz}, 1 \mathrm{H}), 2.43(\mathrm{~d}, J=7.0 \mathrm{~Hz}, 1 \mathrm{H}), 2.42(\mathrm{~d}, J=9.0$ $\mathrm{Hz}, 1 \mathrm{H}), 1.86(\mathrm{~s}, 3 \mathrm{H}), 1.76(\mathrm{~s}, 3 \mathrm{H}), 1.75(\mathrm{~d}, J=6.7 \mathrm{~Hz}, 3 \mathrm{H}), 0.0(\mathrm{~s}, 9 \mathrm{H}) ;{ }^{13} \mathrm{C}-\mathrm{NMR}\left(125 \mathrm{MHz}, \mathrm{CDCl}_{3}\right): \delta$ $167.5,156.6,144.7,142.1,136.9,128.6,125.3,117.3,115.1,80.5,71.0,69.8,56.3,55.1,48.7,39.4$, 37.0, 17.3, 14.3, 12.0, -0.7; IR (film, $\mathrm{cm}^{-1}$ ): 1713, 1250, 1066, 805; HRMS (ESI): calc. for $\mathrm{C}_{23} \mathrm{H}_{34} \mathrm{O}_{3} \mathrm{Si}$ $[\mathrm{M}+\mathrm{Na}]^{+}:$409.21710, obs. 409.21690 . 


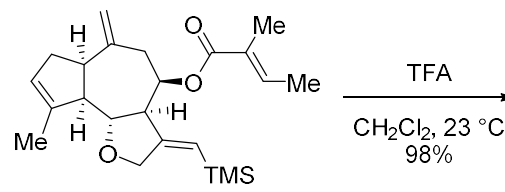

16

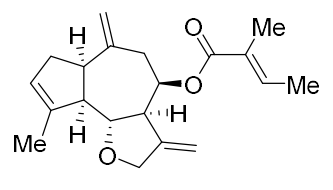

17

To a stirred solution of vinyl silane $16(2 \mathrm{~g}, 5.17 \mathrm{mmol}, 1.0$ equiv. $)$ in $\mathrm{CH}_{2} \mathrm{Cl}_{2}(52 \mathrm{~mL}, 0.1 \mathrm{M})$ was added TFA (3.96 mL, $51.7 \mathrm{mmol}, 10$ equiv.) in a single portion at $23^{\circ} \mathrm{C}$. After 2 hours, the reaction mixture was poured into sat. aq. $\mathrm{NaHCO}_{3}(30 \mathrm{~mL})$ and the aqueous layer was extracted with $\mathrm{CH}_{2} \mathrm{Cl}_{2}(3 \mathrm{x}$ $50 \mathrm{~mL})$. The combined organic layers were washed with sat. aq. $\mathrm{NaHCO}_{3}(3 \times 30 \mathrm{~mL})$, brine $(1 \times 30 \mathrm{~mL})$, dried over $\mathrm{Na}_{2} \mathrm{SO}_{4}$, and concentrated in vacuo to give 17 as an amber oil (1.6 g, $\left.5.09 \mathrm{mmol}, 98 \%\right)$. The crude material was used directly in the next reaction without purification.

$\mathbf{R}_{\boldsymbol{f}}=0.61$ (silica gel, 20:1 hexanes:EtOAc); ${ }^{1} \mathrm{H}-\mathrm{NMR}\left(600 \mathrm{MHz}, \mathrm{CDCl}_{3}\right): \delta 6.79(\mathrm{q}, J=6.14 \mathrm{~Hz}, 1 \mathrm{H}), 5.49$ (s, 1H), $5.44(\mathrm{~m}, 1 \mathrm{H}), 4.94(\mathrm{~m}, 1 \mathrm{H}), 4.91(\mathrm{~s}, 1 \mathrm{H}), 4.85(\mathrm{~m}, 1 \mathrm{H}), 4.75(\mathrm{~s}, 1 \mathrm{H}), 4.40(\mathrm{~d}, J=13.04 \mathrm{~Hz}, 1 \mathrm{H})$, $4.10(\mathrm{dt}, J=2.2,13.09 \mathrm{~Hz}, 1 \mathrm{H}), 3.94(\mathrm{t}, J=9.71 \mathrm{~Hz}, 1 \mathrm{H}), 3.15(\mathrm{t}, J=7.70 \mathrm{~Hz}, 1 \mathrm{H}), 2.70(\mathrm{~m}, 2 \mathrm{H}), 2.64$ (dd, $J=5.44,13.68 \mathrm{~Hz}, 1 \mathrm{H}), 2.42(\mathrm{~m}, 3 \mathrm{H}), 1.86(\mathrm{~s}, 3 \mathrm{H}), 1.77(\mathrm{~s}, 3 \mathrm{H}), 1.75(\mathrm{~s}, 3 \mathrm{H}) .{ }^{13} \mathrm{C}-\mathrm{NMR}(150 \mathrm{MHz}$, $\left.\mathrm{CDCl}_{3}\right): \delta 167.4,148.5,144.6,141.9,137.2,128.6,125.4,115.1,103.6,81.0,71.5,69.4,56.3,52.9,48.4$ 40.1, 37.1, 17.2, 14.3, 12.0. IR (film, $\mathrm{cm}^{-1}$ ): 2367, 2078, 1640, 1401, 1114. HRMS (ESI): calc. for $\mathrm{C}_{20} \mathrm{H}_{26} \mathrm{O}_{3}$ $[\mathrm{M}+\mathrm{H}]^{+}: 315.1955$, obs. 315.1954. 

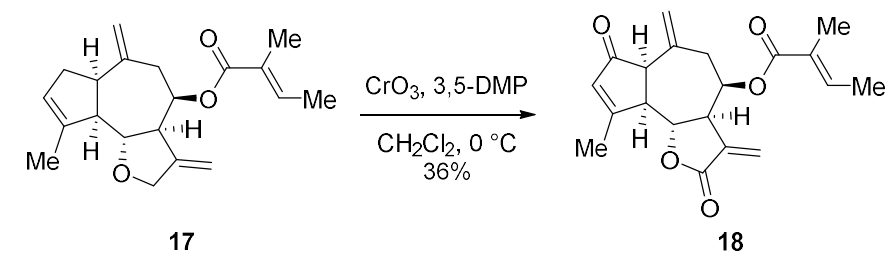

To a stirred solution of $\mathrm{CrO}_{3}(10.18 \mathrm{~g}, 102 \mathrm{mmol}, 20$ equiv. $)$ in $\mathrm{CH}_{2} \mathrm{Cl}_{2}(30 \mathrm{~mL})$ at $0{ }^{\circ} \mathrm{C}$ was added solid 3,5-dimethylpyrazole (9.78 g, $102 \mathrm{mmol}, 20$ equiv.) in a single portion. A solution of carbocycle 17 (1.6 g, 5.09 mmol, 1.0 equiv.) in $\mathrm{CH}_{2} \mathrm{Cl}_{2}(20 \mathrm{~mL})$ was then added. After 30 minutes, the reaction mixture was directly purified via florasil column chromatography (1:1 hexanes:EtOAc) to give a white solid. The white solid was dissolved in EtOAc $(50 \mathrm{ml})$, washed with $1 \mathrm{M} \mathrm{HCl}(3 \times 20 \mathrm{~mL})$, dried over $\mathrm{Na}_{2} \mathrm{SO}_{4}$, and concentrated to give pure guaianolide $18(630 \mathrm{mg}, 5.09 \mathrm{mmol}, 36 \%)$ as a white foam.

$\mathbf{R}_{\boldsymbol{f}}=0.38$ (silica gel, $1: 1$ hexanes:EtOAc); ${ }^{1} \mathrm{H}-\mathrm{NMR}\left(600 \mathrm{MHz}, \mathrm{CDCl}_{3}\right): \delta 6.67(\mathrm{q}, \mathrm{J}=6.97 \mathrm{~Hz}, 1 \mathrm{H}), 6.26(\mathrm{~s}$, 1H), 6.10 (s, 1H), 5.56 (bs, 2H), $4.98(\mathrm{~s}, 1 \mathrm{H}), 4.98(\mathrm{~s}, 1 \mathrm{H}), 4.48(\mathrm{t}, J=9.72 \mathrm{~Hz}, 1 \mathrm{H}), 3.27$ (d, $J=7.30 \mathrm{~Hz}$, 1H), $3.15(\mathrm{~m}, 2 \mathrm{H}), 2.53(\mathrm{~m}, 1 \mathrm{H}), 2.46(\mathrm{~m}, 1 \mathrm{H}), 2.29(\mathrm{~s}, 3 \mathrm{H}), 1.70(\mathrm{~s}, 3 \mathrm{H}), 1.68(\mathrm{~s}, 3 \mathrm{H}) .{ }^{13} \mathrm{C}-\mathrm{NMR}(150$ $\left.\mathrm{MHz}, \mathrm{CDCl}_{3}\right): \delta 205.9,177.6,168.7,166.7,138.5,138.4,133.6,132.6,127.8,122.9,120.4,77.9,66.3$, 55.7, 53.3, 49.4, 41.8, 19.9, 14.4, 11.9. IR (film, $\mathrm{cm}^{-1}$ ): 3438, 3154, 1769, 1704, 1650, 1619. HRMS (ESI): calc. for $\mathrm{C}_{20} \mathrm{H}_{22} \mathrm{O}_{5}[\mathrm{M}+\mathrm{H}]^{+}: 343.1540$, obs. 343.1545 . 

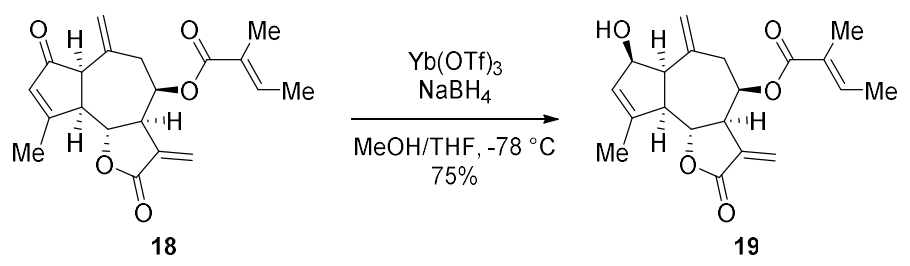

To a stirred solution of enone 18 (630 mg, $1.84 \mathrm{mmol}, 1.0$ equiv.) in 3:1 MeOH:THF (18.4 mL, 0.1 M) at $-78{ }^{\circ} \mathrm{C}$ was added $\mathrm{Yb}(\mathrm{OTf})_{3}(1.25 \mathrm{~g}, 2.02 \mathrm{mmol}, 1.1$ equiv. $)$. After 15 minutes, solid sodium borohydride (84 mg, $2.21 \mathrm{mmol}, 1.2$ equiv.) was added in three even portions every 30 minutes for 1.5 hours. After stirring for an additional 10 minutes, acetaldehyde $(1.0 \mathrm{~mL}, 18.4 \mathrm{mmol}, 10$ equiv.) was added in a single portion and the reaction was stirred further for 15 minutes at $-78{ }^{\circ} \mathrm{C}$. 1:1 EtOAc: $\mathrm{H}_{2} \mathrm{O}(40 \mathrm{~mL})$ was added and the reaction was warmed to $23{ }^{\circ} \mathrm{C}$ over 30 minutes. The reaction mixture was further diluted with brine $(20 \mathrm{~mL})$ and the aqueous layer was extracted with EtOAc $(3 \times 20 \mathrm{~mL})$. The combined organic layers were washed with water $(3 \times 20 \mathrm{~mL})$, brine $(1 \times 20 \mathrm{~mL})$, dried over $\mathrm{Na}_{2} \mathrm{SO}_{4}$ and concentrated in vacuo to give a brown oil. The crude material was purified via silica gel column chromatography (2:1 hexanes:EtOAc) to give pure allylic alcohol 19 (472 mg, $1.37 \mathrm{mmol}, 75 \%)$ as a white foam.

$\mathbf{R}_{\boldsymbol{f}}=0.54$ (silica gel, 2:1 hexanes:EtOAc); ${ }^{1} \mathrm{H}-\mathrm{NMR}\left(400 \mathrm{MHz}, \mathrm{CDCl}_{3}\right): \delta 6.73(\mathrm{q}, J=5.5 \mathrm{~Hz}, 1 \mathrm{H}), 6.29$ (d, $J=3.5 \mathrm{~Hz}, 1 \mathrm{H}), 5.73(\mathrm{bs}, 1 \mathrm{H}), 5.52(\mathrm{dd}, J=11,3.5 \mathrm{~Hz}, 1 \mathrm{H}), 5.51(\mathrm{~d}, J=3.5 \mathrm{~Hz}, 1 \mathrm{H}), 5.12(\mathrm{~s}, 1 \mathrm{H}), 5.11(\mathrm{~s}$ 1H), 4.73 (bs, 1H), 4.66 (dd, $J=11,8.6 \mathrm{~Hz}, 1 \mathrm{H}), 3.19$ (dd, $J=12,2.7 \mathrm{~Hz}, 1 \mathrm{H}), 3.17(\mathrm{~d}, J=5.9 \mathrm{~Hz}, 1 \mathrm{H})$, $2.85(\mathrm{dd}, J=14,6.7 \mathrm{~Hz}, 1 \mathrm{H}), 2.73(\mathrm{dd}, J=14,7.8 \mathrm{~Hz}, 1 \mathrm{H}), 2.68(\mathrm{t}, J=9.4 \mathrm{~Hz}, 1 \mathrm{H}), 1.99(\mathrm{~s}, 3 \mathrm{H}), 1.76(\mathrm{~d}$, $J=5.9 \mathrm{~Hz}, 3 \mathrm{H}), 1.75(\mathrm{~s}, 3 \mathrm{H}), 1.70(\mathrm{~d}, J=5.1 \mathrm{~Hz}, 1 \mathrm{H}) ;{ }^{13} \mathrm{C}-\mathrm{NMR}\left(125 \mathrm{MHz}, \mathrm{CDCl}_{3}\right): \delta$ 169.6, 167.2, 147.3, $141.7,138.3,134.2,129.2,128.0,122.4,119.2,80.8,78.8,67.8,56.1,52.6,47.8,39.1,17.3,14.4,12.0$; IR (film, cm ${ }^{-1}$ ): 3413, 1384, 1137; HRMS (ESI): calc. for $\mathrm{C}_{20} \mathrm{H}_{24} \mathrm{O}_{5}[\mathrm{M}+\mathrm{Na}]^{+}:$367.15160, obs. 367.15200. 


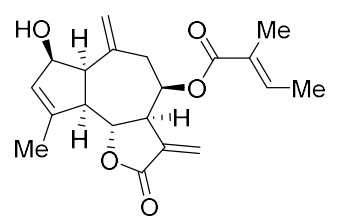

19

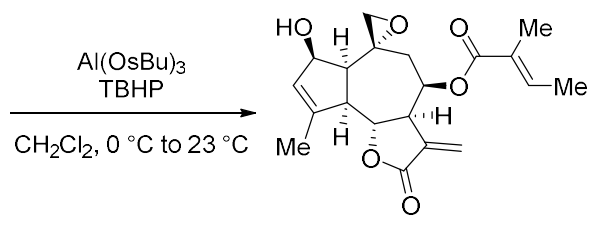

20

To a stirred solution of allylic alcohol 19 (472 mg, $1.37 \mathrm{mmol}, 1.0$ equiv.) in $\mathrm{CH}_{2} \mathrm{Cl}_{2}(13.7 \mathrm{~mL}, 0.1$ M) was added a $1 \mathrm{M}$ solution of $\mathrm{Al}(\mathrm{OsBu})_{3}$ in $\mathrm{CH}_{2} \mathrm{Cl}_{2}(2.1 \mathrm{~mL}, 2.1 \mathrm{mmol}, 1.5$ equiv. $)$ dropwise at $0{ }^{\circ} \mathrm{C}$. The reaction was stirred for 10 minutes before a $5.5-6.0 \mathrm{M}$ solution of TBHP in decane $(0.275 \mathrm{~mL}, 1.51 \mathrm{mmol}$, 1.1 equiv.) was added dropwise. The cooling bath was removed and the reaction was warmed to $23{ }^{\circ} \mathrm{C}$ over 30 minutes. Sat. aq. $\mathrm{Na}_{2} \mathrm{~S}_{2} \mathrm{O}_{3}(10 \mathrm{~mL})$ was added and the mixture was stirred for 15 minutes. The crude reaction was further diluted with brine $(20 \mathrm{~mL})$ and the aqueous layer was extracted with $\mathrm{CH}_{2} \mathrm{Cl}_{2}(3$ $x 20 \mathrm{~mL}$ ). The combined organic layers were dried over $\mathrm{Na}_{2} \mathrm{SO}_{4}$ and concentrated to give epoxide 20 as a clear oil. The crude material was used immediately in the next reaction without purification.

$\mathbf{R}_{\boldsymbol{f}}=0.54$ (silica gel, 1:1 hexanes:EtOAc); ${ }^{1} \mathrm{H}-\mathrm{NMR}\left(600 \mathrm{MHz}, \mathrm{CDCl}_{3}\right): \delta 6.70(\mathrm{q}, J=6.4 \mathrm{~Hz}, 1 \mathrm{H}), 6.33(\mathrm{~d}$, $J=3.2 \mathrm{~Hz}, 1 \mathrm{H}), 5.71(\mathrm{bs}, 1 \mathrm{H}), 5.57(\mathrm{td}, J=8.6,4.7 \mathrm{~Hz}, 1 \mathrm{H}), 5.55(\mathrm{~d}, J=2.8 \mathrm{~Hz}, 1 \mathrm{H}), 4.68(\mathrm{bs}, 1 \mathrm{H}), 4.67$ (t, $J=8.8 \mathrm{~Hz}, 1 \mathrm{H}), 3.56(\mathrm{dd}, J=8.6,4.7 \mathrm{~Hz}, 1 \mathrm{H}), 2.79(\mathrm{q}, J=7.6 \mathrm{~Hz}, 1 \mathrm{H}), 2.77(\mathrm{t}, J=9.6 \mathrm{~Hz}, 1 \mathrm{H}), 2.61$ (dd, $J=14,7.6 \mathrm{~Hz}, 1 \mathrm{H}), 2.35(\mathrm{~d}, J=9.2 \mathrm{~Hz}, 1 \mathrm{H}), 2.25$ (dd, $J=15,8.4 \mathrm{~Hz}, 1 \mathrm{H}), 2.01(\mathrm{~s}, 3 \mathrm{H}), 1.97$ (d, $J=$ $7.2 \mathrm{~Hz}, 1 \mathrm{H}), 1.77$ (s, 3H), 1.73 (s, 3H); ${ }^{13} \mathrm{C}-\mathrm{NMR}\left(150 \mathrm{MHz}, \mathrm{CDCl}_{3}\right): \delta$ 169.6, 167.1, 148.9, 138.3, 133.9, 128.9, 127.9, 122.9, 81.0, 76.75, 66.7, 56.3, 55.7, 55.4, 52.3, 47.8, 36.5, 17.4, 14.3, 12.0; IR (film, $\left.\mathrm{cm}^{-1}\right)$ : 3477, 1768, 1339, 1140, 1037; HRMS (ESI): calc. for $\mathrm{C}_{20} \mathrm{H}_{24} \mathrm{O}_{6}[\mathrm{M}+\mathrm{Na}]^{+}: 383.14650$, obs. 383.14680. 


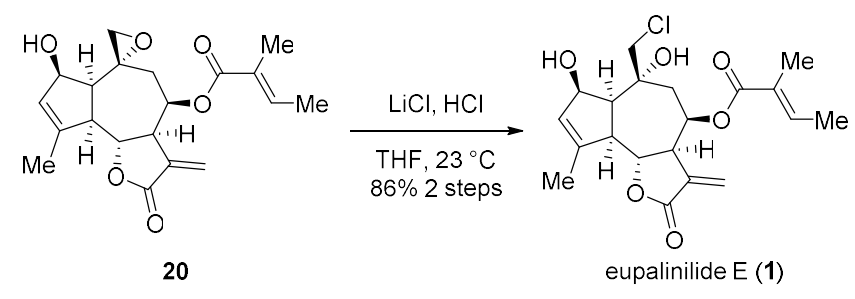

eupalinilide $E(1)$

To a stirred solution of crude epoxide 20 (490 mg, $1.36 \mathrm{mmol}, 1.0$ equiv.) in THF (13.6 mL, $0.1 \mathrm{M})$ at $23{ }^{\circ} \mathrm{C}$ was added solid lithium chloride (576 mg, $13.6 \mathrm{mmol}, 10.0$ equiv.) in a single portion. The mixture of sonicated for 5 minutes before addition of a $1.25 \mathrm{M}$ solution of hydrochloric acid in $\mathrm{MeOH}$ (3.26 $\mathrm{mL}, 4.08 \mathrm{mmol}, 3.0$ equiv.). After 5 minutes, the reaction mixture was diluted with brine $(40.0 \mathrm{~mL})$, extracted with EA $(3 \times 30 \mathrm{~mL})$, dried over $\mathrm{Na}_{2} \mathrm{SO}_{4}$, and concentrated in vacuo to give a white solid. The crude material was purified via silica gel column chromatography (2:1 hexanes:EtOAc) to give pure eupalinilide $E$ (1) (466 mg, $1.36 \mathrm{mmol}, 86 \%$ over two steps) as a white solid (m.p. $72^{\circ} \mathrm{C}$, decomp.).

$\mathbf{R}_{\boldsymbol{f}}=0.63$ (silica gel, 1:1 hexanes:EtOAc); $[\alpha]^{20}{ }_{\mathrm{D}}=-97.9\left(\mathrm{c}=1.0\right.$ in $\left.\mathrm{CHCl}_{3}\right) ;{ }^{1} \mathrm{H}-\mathbf{N M R}\left(600 \mathrm{MHz}, \mathrm{CDCl}_{3}\right): \delta$ $6.70(\mathrm{q}, J=5.5 \mathrm{~Hz}, 1 \mathrm{H}), 6.27(\mathrm{~d}, J=3.5 \mathrm{~Hz}, 1 \mathrm{H}), 5.75(\mathrm{bs}, 1 \mathrm{H}), 5.65(\mathrm{td}, J=8.6,4.7 \mathrm{~Hz}, 1 \mathrm{H}), 5.45(\mathrm{~d}, J=$ $3.5 \mathrm{~Hz}, 1 \mathrm{H}), 4.59(\mathrm{bs}, 1 \mathrm{H}), 4.58(\mathrm{t}, J=8.6 \mathrm{~Hz}, 1 \mathrm{H}), 3.94(\mathrm{~d}, J=11 \mathrm{~Hz}, 1 \mathrm{H}), 3.93(\mathrm{bs}, 1 \mathrm{H}), 3.67(\mathrm{~d}, J=11$ $\mathrm{Hz}, 1 \mathrm{H}), 2.77(\mathrm{dd}, J=11,7.4 \mathrm{~Hz}, 1 \mathrm{H}), 2.50-2.44(\mathrm{~m}, 4 \mathrm{H}), 2.04(\mathrm{~s}, 3 \mathrm{H}), 1.74(\mathrm{~d}, J=5.3 \mathrm{~Hz}, 3 \mathrm{H}), 1.73$ (s, 3H); ${ }^{13}$ C-NMR (150 MHz, $\left.\mathrm{CDCl}_{3}\right): \delta$ 169.7, 167.2, 150.6, 138.1, 134.4, 128.6, 128.1, 122.1, 82.0, 75.1, 73.6, 66.4, 55.2, 55.0, 52.2, 47.4, 36.4, 18.0, 14.4, 12.0; IR (film, $\left.\mathrm{cm}^{-1}\right)$ : 3409, 1654, 1384, 1129; HRMS (ESI): calc. for $\mathrm{C}_{20} \mathrm{H}_{25} \mathrm{ClO}_{6}[\mathrm{M}+\mathrm{Na}]^{+}: 419.12320$, obs. 419.1229 


\section{X-Ray Crystallographic Data}

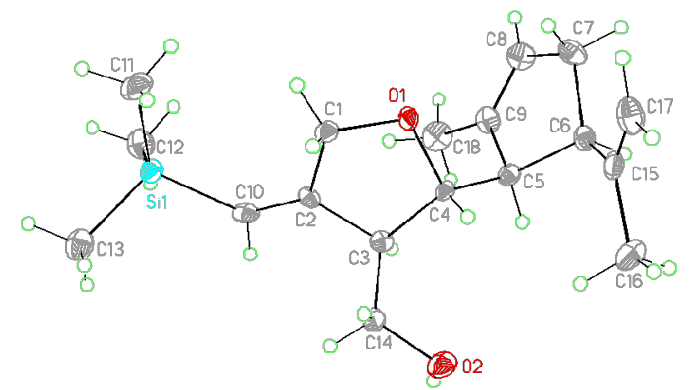

Table S1. Crystal data and structure refinement for 13.

Empirical formula

Formula weight

Temperature

Wavelength

Crystal system

Space group

Unit cell dimensions

Volume

Z

Density (calculated)

Absorption coefficient

$\mathrm{F}(000)$

Crystal size

Theta range for data collection

Index ranges

Reflections collected

Independent reflections

Completeness to theta $=25.242^{\circ}$

Absorption correction

Max. and min. transmission
$\mathrm{C} 18 \mathrm{H} 30 \mathrm{O} 2 \mathrm{Si}$

306.51

133(2) K

$0.71073 \AA$

monoclinic

P 21

$a=10.9429(18) \AA$

$\alpha=90^{\circ}$.

$\mathrm{b}=6.4395(12) \AA$

$\beta=102 \cdot 480(6)^{\circ}$.

$c=13.070(3) \AA$ $\gamma=90^{\circ}$.
899.2(3) $\AA^{3}$

2

$1.132 \mathrm{Mg} / \mathrm{m}^{3}$

$0.134 \mathrm{~mm}^{-1}$

336

$0.39 \times 0.15 \times 0.10 \mathrm{~mm}$

3.544 to $25.464^{\circ}$.

$-13<=\mathrm{h}<=9,-7<=\mathrm{k}<=7,-15<=\mid<=15$

5362

$3151[R($ int $)=0.0478]$

$98.6 \%$

Semi-empirical from equivalents

1.00 and 0.923 
Refinement method

Data / restraints / parameters

Goodness-of-fit on $\mathrm{F}^{2}$

Final $R$ indices [l>2sigma(I)]

$\mathrm{R}$ indices (all data)

Absolute structure parameter

Extinction coefficient

Largest diff. peak and hole
Full-matrix least-squares on $\mathrm{F}^{2}$

$3151 / 1 / 199$

1.062

$\mathrm{R} 1=0.0606, \mathrm{wR} 2=0.1078$

$\mathrm{R} 1=0.0926, \mathrm{wR} 2=0.1184$

$0.02(16)$

$\mathrm{n} / \mathrm{a}$

0.395 and -0.235 e. $\AA^{-3}$

Table S2. Atomic coordinates $\left(\times 10^{4}\right)$ and equivalent isotropic displacement parameters $\left(\AA^{2} \times 10^{3}\right)$ for 13. $U(e q)$ is defined as one third of the trace of the orthogonalized $U i j$ tensor.

\begin{tabular}{|c|c|c|c|c|}
\hline & $x$ & $y$ & z & $\mathrm{U}(\mathrm{eq})$ \\
\hline $\mathrm{C} 1$ & $5035(5)$ & $6449(7)$ & $2871(4)$ & $16(1)$ \\
\hline $\mathrm{C} 2$ & $5046(4)$ & $8692(8)$ & $2499(4)$ & 13(1) \\
\hline $\mathrm{C} 3$ & $4088(5)$ & $9811(8)$ & $2976(4)$ & $14(1)$ \\
\hline $\mathrm{C} 4$ & $3341(4)$ & $8073(7)$ & $3380(4)$ & $12(1)$ \\
\hline C5 & $1921(4)$ & $8183(8)$ & 2992(4) & $15(1)$ \\
\hline C6 & $1135(5)$ & $6748(7)$ & $3579(4)$ & $17(1)$ \\
\hline $\mathrm{C} 7$ & $917(5)$ & $4763(8)$ & $2903(4)$ & $24(1)$ \\
\hline C8 & $939(5)$ & $5602(9)$ & $1831(5)$ & $24(1)$ \\
\hline $\mathrm{Cg}$ & $1482(5)$ & $7454(8)$ & $1866(4)$ & $21(1)$ \\
\hline $\mathrm{C} 10$ & $5753(4)$ & $9550(8)$ & 1899(4) & $18(1)$ \\
\hline $\mathrm{C} 11$ & $7376(6)$ & $5758(8)$ & $1539(5)$ & $35(2)$ \\
\hline $\mathrm{C} 12$ & $6430(5)$ & $8968(9)$ & $-189(5)$ & $34(2)$ \\
\hline $\mathrm{C} 13$ & $8431(5)$ & 10151(9) & $1705(5)$ & $28(2)$ \\
\hline $\mathrm{C} 14$ & $4774(5)$ & 11226(8) & $3853(4)$ & $18(1)$ \\
\hline C15 & $1615(5)$ & $6523(8)$ & $4739(4)$ & $20(1)$ \\
\hline $\mathrm{C} 16$ & $1716(5)$ & $8541(10)$ & $5356(4)$ & $29(1)$ \\
\hline $\mathrm{C} 17$ & $1880(5)$ & $4720(9)$ & $5225(5)$ & $28(2)$ \\
\hline C18 & $1693(5)$ & $8661(10)$ & $934(4)$ & $30(1)$ \\
\hline O1 & $3809(3)$ & $6122(5)$ & $3058(3)$ & $20(1)$ \\
\hline $\mathrm{O} 2$ & $3913(4)$ & $12361(6)$ & $4328(3)$ & $26(1)$ \\
\hline Si1 & $6991(1)$ & $8566(2)$ & 1248(1) & $18(1)$ \\
\hline
\end{tabular}


Table S3. Bond lengths $[\AA]$ and angles $\left[{ }^{\circ}\right]$ for 13 .

\begin{tabular}{|c|c|c|c|}
\hline C1-O1 & $1.430(5)$ & C11-Si1 & $1.877(6)$ \\
\hline C1-C2 & $1.525(7)$ & $\mathrm{C} 11-\mathrm{H} 11 \mathrm{~A}$ & 0.98 \\
\hline $\mathrm{C} 1-\mathrm{H} 1 \mathrm{~A}$ & 0.99 & $\mathrm{C} 11-\mathrm{H} 11 \mathrm{~B}$ & 0.98 \\
\hline C1-H1B & 0.99 & $\mathrm{C} 11-\mathrm{H} 11 \mathrm{C}$ & 0.98 \\
\hline $\mathrm{C} 2-\mathrm{C} 10$ & $1.335(6)$ & C12-Si1 & $1.864(6)$ \\
\hline $\mathrm{C} 2-\mathrm{C} 3$ & $1.513(7)$ & $\mathrm{C} 12-\mathrm{H} 12 \mathrm{~A}$ & 0.98 \\
\hline C3-C14 & $1.528(7)$ & $\mathrm{C} 12-\mathrm{H} 12 \mathrm{~B}$ & 0.98 \\
\hline C3-C4 & $1.544(6)$ & $\mathrm{C} 12-\mathrm{H} 12 \mathrm{C}$ & 0.98 \\
\hline $\mathrm{C} 3-\mathrm{H} 3$ & 1.00 & C13-Si1 & $1.864(6)$ \\
\hline $\mathrm{C} 4-\mathrm{O} 1$ & $1.453(6)$ & $\mathrm{C} 13-\mathrm{H} 13 \mathrm{~A}$ & 0.98 \\
\hline C4-C5 & $1.528(6)$ & $\mathrm{C} 13-\mathrm{H} 13 \mathrm{~B}$ & 0.98 \\
\hline $\mathrm{C} 4-\mathrm{H} 4$ & 1.00 & $\mathrm{C} 13-\mathrm{H} 13 \mathrm{C}$ & 0.98 \\
\hline C5-C9 & $1.521(7)$ & $\mathrm{C} 14-\mathrm{O} 2$ & $1.435(6)$ \\
\hline C5-C6 & $1.571(7)$ & $\mathrm{C} 14-\mathrm{H} 14 \mathrm{~A}$ & 0.99 \\
\hline $\mathrm{C} 5-\mathrm{H} 5$ & 1.00 & $\mathrm{C} 14-\mathrm{H} 14 \mathrm{~B}$ & 0.99 \\
\hline C6-C15 & $1.500(7)$ & C15-C17 & $1.325(7)$ \\
\hline $\mathrm{C} 6-\mathrm{C} 7$ & $1.543(7)$ & C15-C16 & $1.521(8)$ \\
\hline $\mathrm{C} 6-\mathrm{H} 6$ & 1.00 & $\mathrm{C} 16-\mathrm{H} 16 \mathrm{~A}$ & 0.98 \\
\hline C7-C8 & $1.507(8)$ & $\mathrm{C} 16-\mathrm{H} 16 \mathrm{~B}$ & 0.98 \\
\hline C7-H7A & 0.99 & $\mathrm{C} 16-\mathrm{H} 16 \mathrm{C}$ & 0.98 \\
\hline C7-H7B & 0.99 & $\mathrm{C} 17-\mathrm{H} 17 \mathrm{~A}$ & 0.95 \\
\hline C8-C9 & $1.329(7)$ & C17-H17B & 0.95 \\
\hline $\mathrm{C} 8-\mathrm{H} 8$ & 0.95 & $\mathrm{C} 18-\mathrm{H} 18 \mathrm{~A}$ & 0.98 \\
\hline C9-C18 & $1.505(7)$ & $\mathrm{C} 18-\mathrm{H} 18 \mathrm{~B}$ & 0.98 \\
\hline C10-Si1 & $1.860(5)$ & $\mathrm{C} 18-\mathrm{H} 18 \mathrm{C}$ & 0.98 \\
\hline $\mathrm{C} 10-\mathrm{H} 10$ & 0.95 & $\mathrm{O} 2-\mathrm{H} 2 \mathrm{O}$ & $0.83(6)$ \\
\hline $\mathrm{O} 1-\mathrm{C} 1-\mathrm{C} 2$ & $105.5(4)$ & $\mathrm{C} 3-\mathrm{C} 2-\mathrm{C} 1$ & $105.4(4)$ \\
\hline O1-C1-H1A & 110.6 & C2-C3-C14 & $108.7(4)$ \\
\hline $\mathrm{C} 2-\mathrm{C} 1-\mathrm{H} 1 \mathrm{~A}$ & 110.6 & $\mathrm{C} 2-\mathrm{C} 3-\mathrm{C} 4$ & $105.1(4)$ \\
\hline O1-C1-H1B & 110.6 & C14-C3-C4 & $112.7(4)$ \\
\hline $\mathrm{C} 2-\mathrm{C} 1-\mathrm{H} 1 \mathrm{~B}$ & 110.6 & $\mathrm{C} 2-\mathrm{C} 3-\mathrm{H} 3$ & 110.0 \\
\hline $\mathrm{H} 1 \mathrm{~A}-\mathrm{C} 1-\mathrm{H} 1 \mathrm{~B}$ & 108.8 & C14-C3-H3 & 110.0 \\
\hline C10-C2-C3 & $125.9(5)$ & $\mathrm{C} 4-\mathrm{C} 3-\mathrm{H} 3$ & 110.0 \\
\hline C10-C2-C1 & $128.7(4)$ & O1-C4-C5 & $109.9(4)$ \\
\hline
\end{tabular}




\begin{tabular}{|c|c|c|c|}
\hline O1-C4-C3 & $106.4(4)$ & $\mathrm{H} 11 \mathrm{~A}-\mathrm{C} 11-\mathrm{H} 11 \mathrm{C}$ & 109.5 \\
\hline $\mathrm{C} 5-\mathrm{C} 4-\mathrm{C} 3$ & $115.4(4)$ & H11B-C11-H11C & 109.5 \\
\hline O1-C4-H4 & 108.3 & $\mathrm{Si1}-\mathrm{C} 12-\mathrm{H} 12 \mathrm{~A}$ & 109.5 \\
\hline C5-C4-H4 & 108.3 & Si1-C12-H12B & 109.5 \\
\hline C3-C4-H4 & 108.3 & $\mathrm{H} 12 \mathrm{~A}-\mathrm{C} 12-\mathrm{H} 12 \mathrm{~B}$ & 109.5 \\
\hline C9-C5-C4 & $113.1(4)$ & $\mathrm{Si1}-\mathrm{C} 12-\mathrm{H} 12 \mathrm{C}$ & 109.5 \\
\hline C9-C5-C6 & $101.5(4)$ & $\mathrm{H} 12 \mathrm{~A}-\mathrm{C} 12-\mathrm{H} 12 \mathrm{C}$ & 109.5 \\
\hline C4-C5-C6 & $115.8(4)$ & $\mathrm{H} 12 \mathrm{~B}-\mathrm{C} 12-\mathrm{H} 12 \mathrm{C}$ & 109.5 \\
\hline C9-C5-H5 & 108.7 & Si1-C13-H13A & 109.5 \\
\hline C4-C5-H5 & 108.7 & Si1-C13-H13B & 109.5 \\
\hline C6-C5-H5 & 108.7 & $\mathrm{H} 13 \mathrm{~A}-\mathrm{C} 13-\mathrm{H} 13 \mathrm{~B}$ & 109.5 \\
\hline C15-C6-C7 & $118.4(4)$ & $\mathrm{Si1}-\mathrm{C} 13-\mathrm{H} 13 \mathrm{C}$ & 109.5 \\
\hline C15-C6-C5 & $116.2(4)$ & $\mathrm{H} 13 \mathrm{~A}-\mathrm{C} 13-\mathrm{H} 13 \mathrm{C}$ & 109.5 \\
\hline C7-C6-C5 & $103.9(4)$ & $\mathrm{H} 13 \mathrm{~B}-\mathrm{C} 13-\mathrm{H} 13 \mathrm{C}$ & 109.5 \\
\hline C15-C6-H6 & 105.8 & $\mathrm{O} 2-\mathrm{C} 14-\mathrm{C} 3$ & $111.4(4)$ \\
\hline C7-C6-H6 & 105.8 & $\mathrm{O} 2-\mathrm{C} 14-\mathrm{H} 14 \mathrm{~A}$ & 109.3 \\
\hline C5-C6-H6 & 105.8 & C3-C14-H14A & 109.3 \\
\hline C8-C7-C6 & $101.8(4)$ & O2-C14-H14B & 109.3 \\
\hline C8-C7-H7A & 111.4 & C3-C14-H14B & 109.3 \\
\hline C6-C7-H7A & 111.4 & $\mathrm{H} 14 \mathrm{~A}-\mathrm{C} 14-\mathrm{H} 14 \mathrm{~B}$ & 108.0 \\
\hline C8-C7-H7B & 111.4 & C17-C15-C6 & $124.2(5)$ \\
\hline C6-C7-H7B & 111.4 & C17-C15-C16 & $120.7(5)$ \\
\hline H7A-C7-H7B & 109.3 & C6-C15-C16 & $115.0(5)$ \\
\hline C9-C8-C7 & $112.7(5)$ & C15-C16-H16A & 109.5 \\
\hline C9-C8-H8 & 123.6 & C15-C16-H16B & 109.5 \\
\hline C7-C8-H8 & 123.6 & H16A-C16-H16B & 109.5 \\
\hline C8-C9-C18 & $125.5(6)$ & C15-C16-H16C & 109.5 \\
\hline C8-C9-C5 & $110.9(5)$ & $\mathrm{H} 16 \mathrm{~A}-\mathrm{C} 16-\mathrm{H} 16 \mathrm{C}$ & 109.5 \\
\hline C18-C9-C5 & $123.5(5)$ & H16B-C16-H16C & 109.5 \\
\hline C2-C10-Si1 & $134.4(4)$ & C15-C17-H17A & 120.0 \\
\hline C2-C10-H10 & 112.8 & C15-C17-H17B & 120.0 \\
\hline Si1-C10-H10 & 112.8 & H17A-C17-H17B & 120.0 \\
\hline Si1-C11-H11A & 109.5 & C9-C18-H18A & 109.5 \\
\hline Si1-C11-H11B & 109.5 & C9-C18-H18B & 109.5 \\
\hline $\mathrm{H} 11 \mathrm{~A}-\mathrm{C} 11-\mathrm{H} 11 \mathrm{~B}$ & 109.5 & $\mathrm{H} 18 \mathrm{~A}-\mathrm{C} 18-\mathrm{H} 18 \mathrm{~B}$ & 109.5 \\
\hline Si1-C11-H11C & 109.5 & C9-C18-H18C & 109.5 \\
\hline
\end{tabular}




$\begin{array}{lllr}\mathrm{H} 18 \mathrm{~A}-\mathrm{C} 18-\mathrm{H} 18 \mathrm{C} & 109.5 & \mathrm{C} 10-\mathrm{Si1}-\mathrm{C} 12 & 107.4(3) \\ \mathrm{H} 18 \mathrm{~B}-\mathrm{C} 18-\mathrm{H} 18 \mathrm{C} & 109.5 & \mathrm{C} 13-\mathrm{Si1}-\mathrm{C} 12 & 108.6(3) \\ \mathrm{C} 1-\mathrm{O} 1-\mathrm{C} 4 & 109.0(3) & \mathrm{C} 10-\mathrm{Si1}-\mathrm{C} 11 & 112.9(2) \\ \mathrm{C} 14-\mathrm{O} 2-\mathrm{H} 2 \mathrm{O} & 102(4) & \mathrm{C} 13-\mathrm{Si1}-\mathrm{C} 11 & 109.0(3) \\ \mathrm{C} 10-\mathrm{Si1}-\mathrm{C} 13 & 108.4(2) & \mathrm{C} 12-\mathrm{Si1}-\mathrm{C} 11 & 110.4(3)\end{array}$

Table S4. Anisotropic displacement parameters $\left(\AA^{2} \times 10^{3}\right)$ for 13. The anisotropic displacement factor exponent takes the form: $-2 \pi^{2}\left[h^{2} a^{* 2} U^{11}+\ldots+2 h k a^{*} b^{*} U^{12}\right]$

\begin{tabular}{|c|c|c|c|c|c|c|}
\hline & $U^{11}$ & $\mathrm{U}^{22}$ & $u^{33}$ & $U^{23}$ & $u^{13}$ & $U^{12}$ \\
\hline C1 & $17(3)$ & $12(3)$ & $18(3)$ & $0(2)$ & $5(2)$ & $3(2)$ \\
\hline $\mathrm{C} 2$ & $14(2)$ & $10(3)$ & $15(3)$ & $5(3)$ & $2(2)$ & $-1(3)$ \\
\hline C3 & $18(3)$ & $12(3)$ & $13(3)$ & $3(2)$ & $3(3)$ & $1(2)$ \\
\hline C4 & $14(2)$ & $10(3)$ & $14(3)$ & $1(2)$ & $6(2)$ & $3(2)$ \\
\hline C5 & $16(3)$ & $14(3)$ & $16(3)$ & $1(2)$ & $4(2)$ & $3(2)$ \\
\hline C6 & $12(3)$ & $18(3)$ & $21(4)$ & $3(2)$ & $4(3)$ & $2(2)$ \\
\hline $\mathrm{C} 7$ & $22(3)$ & $23(3)$ & $24(4)$ & $-2(3)$ & $0(3)$ & $-6(3)$ \\
\hline $\mathrm{C} 8$ & $21(3)$ & $32(4)$ & $17(4)$ & $-6(3)$ & $-3(3)$ & $-4(3)$ \\
\hline C9 & $13(3)$ & $25(3)$ & $21(4)$ & $2(3)$ & $-1(3)$ & $2(2)$ \\
\hline C10 & $21(3)$ & $9(3)$ & $21(4)$ & $2(2)$ & $0(3)$ & $3(2)$ \\
\hline C11 & $44(4)$ & $17(3)$ & $49(5)$ & $-1(3)$ & $24(4)$ & $5(3)$ \\
\hline C12 & $35(3)$ & $32(4)$ & $37(4)$ & $-1(3)$ & $17(3)$ & $-5(3)$ \\
\hline C13 & $27(3)$ & $26(3)$ & $31(4)$ & $5(3)$ & $7(3)$ & $6(3)$ \\
\hline C14 & $17(3)$ & $13(3)$ & $27(4)$ & $1(3)$ & $7(3)$ & $2(2)$ \\
\hline C15 & $17(3)$ & $26(3)$ & $20(4)$ & $-1(3)$ & $10(3)$ & $0(3)$ \\
\hline C16 & $33(3)$ & $30(3)$ & $25(3)$ & $-6(3)$ & $12(3)$ & $3(3)$ \\
\hline C17 & $27(3)$ & $34(4)$ & $24(4)$ & $8(3)$ & $9(3)$ & $-2(3)$ \\
\hline C18 & $30(3)$ & $34(3)$ & $22(3)$ & $2(3)$ & $0(3)$ & $3(3)$ \\
\hline 01 & $13(2)$ & $12(2)$ & $36(3)$ & $2(2)$ & $11(2)$ & $3(2)$ \\
\hline $\mathrm{O} 2$ & $37(3)$ & $15(2)$ & $31(3)$ & $0(2)$ & $15(2)$ & $3(2)$ \\
\hline Si1 & $21(1)$ & $16(1)$ & $20(1)$ & $2(1)$ & $9(1)$ & $2(1)$ \\
\hline
\end{tabular}


Table S5. Hydrogen coordinates $\left(\times 10^{4}\right)$ and isotropic displacement parameters $\left(\AA^{2} \times 10^{3}\right)$ for 13 .

\begin{tabular}{|c|c|c|c|c|}
\hline & $x$ & $y$ & $z$ & $\mathrm{U}(\mathrm{eq})$ \\
\hline $\mathrm{H} 1 \mathrm{~A}$ & 5199 & 5481 & 2327 & 19 \\
\hline H1B & 5679 & 6234 & 3521 & 19 \\
\hline $\mathrm{H} 3$ & 3519 & 10652 & 2429 & 17 \\
\hline $\mathrm{H} 4$ & 3536 & 8124 & 4163 & 14 \\
\hline $\mathrm{H} 5$ & 1647 & 9654 & 3043 & 18 \\
\hline $\mathrm{H} 6$ & 296 & 7427 & 3491 & 21 \\
\hline $\mathrm{H} 7 \mathrm{~A}$ & 1593 & 3735 & 3136 & 28 \\
\hline H7B & 100 & 4116 & 2918 & 28 \\
\hline $\mathrm{H} 8$ & 600 & 4884 & 1198 & 29 \\
\hline $\mathrm{H} 10$ & 5586 & 10987 & 1776 & 21 \\
\hline $\mathrm{H} 11 \mathrm{~A}$ & 8083 & 5356 & 1232 & 52 \\
\hline $\mathrm{H} 11 \mathrm{~B}$ & 6647 & 4901 & 1238 & 52 \\
\hline $\mathrm{H} 11 \mathrm{C}$ & 7599 & 5549 & 2300 & 52 \\
\hline $\mathrm{H} 12 \mathrm{~A}$ & 6193 & 10426 & -326 & 50 \\
\hline $\mathrm{H} 12 \mathrm{~B}$ & 5702 & 8080 & -448 & 50 \\
\hline $\mathrm{H} 12 \mathrm{C}$ & 7099 & 8611 & -549 & 50 \\
\hline $\mathrm{H} 13 \mathrm{~A}$ & 8245 & 11613 & 1529 & 41 \\
\hline H13B & 9090 & 9667 & 1361 & 41 \\
\hline $\mathrm{H} 13 \mathrm{C}$ & 8714 & 10007 & 2466 & 41 \\
\hline $\mathrm{H} 14 \mathrm{~A}$ & 5328 & 10376 & 4394 & 22 \\
\hline $\mathrm{H} 14 \mathrm{~B}$ & 5305 & 12215 & 3565 & 22 \\
\hline $\mathrm{H} 16 \mathrm{~A}$ & 2006 & 8244 & 6105 & 43 \\
\hline H16B & 893 & 9211 & 5237 & 43 \\
\hline $\mathrm{H} 16 \mathrm{C}$ & 2313 & 9469 & 5125 & 43 \\
\hline $\mathrm{H} 17 \mathrm{~A}$ & 1767 & 3463 & 4835 & 33 \\
\hline H17B & 2182 & 4684 & 5963 & 33 \\
\hline $\mathrm{H} 18 \mathrm{~A}$ & 2587 & 8660 & 929 & 44 \\
\hline $\mathrm{H} 18 \mathrm{~B}$ & 1406 & 10094 & 976 & 44 \\
\hline $\mathrm{H} 18 \mathrm{C}$ & 1223 & 8015 & 289 & 44 \\
\hline $\mathrm{H} 2 \mathrm{O}$ & $3720(50)$ & $13360(100)$ & $3920(50)$ & $40(20)$ \\
\hline
\end{tabular}


Table S6. Torsion angles $\left[{ }^{\circ}\right]$ for 13.

\begin{tabular}{lclc}
\hline O1-C1-C2-C10 & $-154.5(5)$ & C7-C8-C9-C18 & $177.5(5)$ \\
O1-C1-C2-C3 & $26.7(5)$ & C7-C8-C9-C5 & $-0.2(6)$ \\
C10-C2-C3-C14 & $-71.2(6)$ & C4-C5-C9-C8 & $106.6(5)$ \\
C1-C2-C3-C14 & $107.7(5)$ & C6-C5-C9-C8 & $-18.2(5)$ \\
C10-C2-C3-C4 & $167.9(5)$ & C4-C5-C9-C18 & $-71.1(6)$ \\
C1-C2-C3-C4 & $-13.3(5)$ & C6-C5-C9-C18 & $164.1(5)$ \\
C2-C3-C4-O1 & $-4.3(5)$ & C3-C2-C10-Si1 & $178.7(4)$ \\
C14-C3-C4-O1 & $-122.6(4)$ & C1-C2-C10-Si1 & $0.1(9)$ \\
C2-C3-C4-C5 & $-126.5(4)$ & C2-C3-C14-O2 & $179.0(4)$ \\
C14-C3-C4-C5 & $115.2(5)$ & C4-C3-C14-O2 & $-64.8(5)$ \\
O1-C4-C5-C9 & $-43.9(5)$ & C7-C6-C15-C17 & $0.7(8)$ \\
C3-C4-C5-C9 & $76.4(6)$ & C5-C6-C15-C17 & $-124.1(6)$ \\
O1-C4-C5-C6 & $72.7(5)$ & C7-C6-C15-C16 & $-175.8(5)$ \\
C3-C4-C5-C6 & $-167.0(4)$ & C5-C6-C15-C16 & $59.4(6)$ \\
C9-C5-C6-C15 & $160.4(4)$ & C2-C1-O1-C4 & $-30.4(5)$ \\
C4-C5-C6-C15 & $37.5(6)$ & C5-C4-O1-C1 & $147.5(4)$ \\
C9-C5-C6-C7 & $28.6(5)$ & C3-C4-O1-C1 & $21.9(5)$ \\
C4-C5-C6-C7 & $-94.4(5)$ & C2-C10-Si1-C13 & $-123.5(5)$ \\
C15-C6-C7-C8 & $-159.1(4)$ & C2-C10-Si1-C12 & $119.3(5)$ \\
C5-C6-C7-C8 & $-28.6(5)$ & C2-C10-Si1-C11 & $-2.6(6)$ \\
C6-C7-C8-C9 & $18.8(6)$ & &
\end{tabular}

Table S7. Hydrogen bonds for 13 [ $\AA$ and $\left.{ }^{\circ}\right]$.

\begin{tabular}{lllll}
\hline D-H...A & $d(D-H)$ & $d(H \ldots A)$ & $d(D \ldots A)$ & $<(D H A)$ \\
\hline O2-H2O...01\#1 & $0.83(6)$ & $2.12(6)$ & $2.924(6)$ & $163(5)$ \\
\hline
\end{tabular}

Symmetry transformations used to generate equivalent atoms:

\#1 $x, y+1, z$ 
IV. Spectral Data

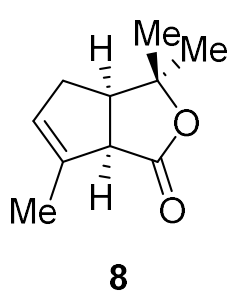

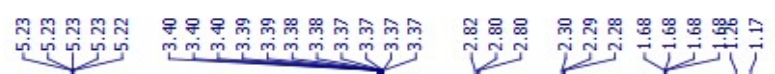

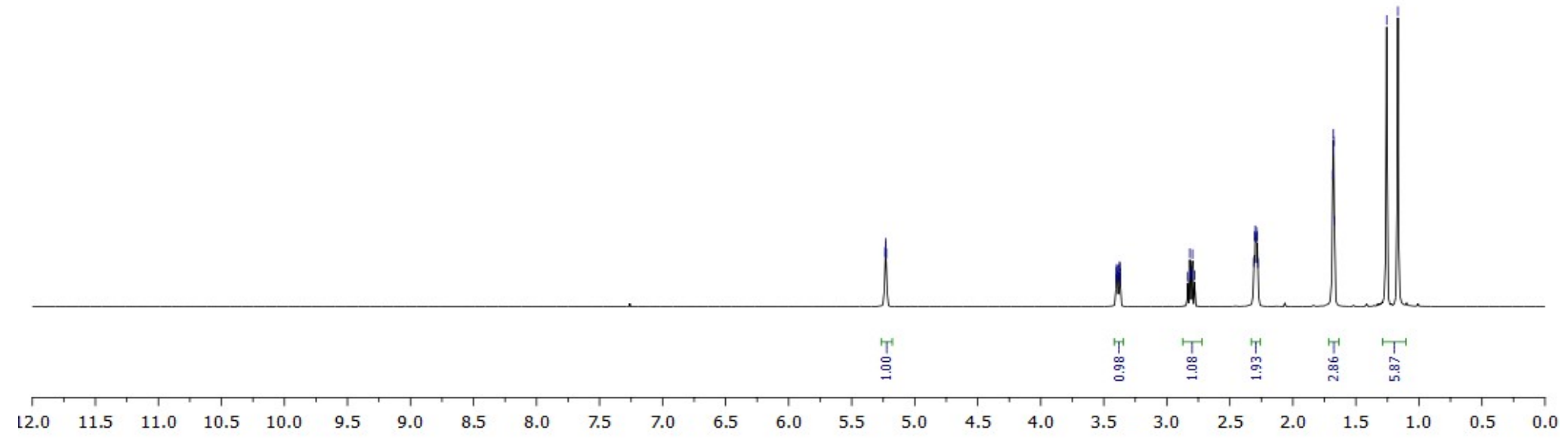

S-28 


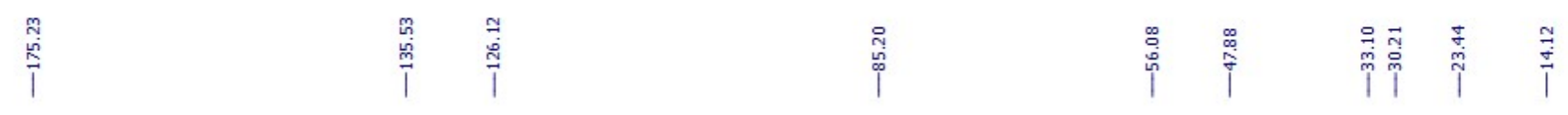
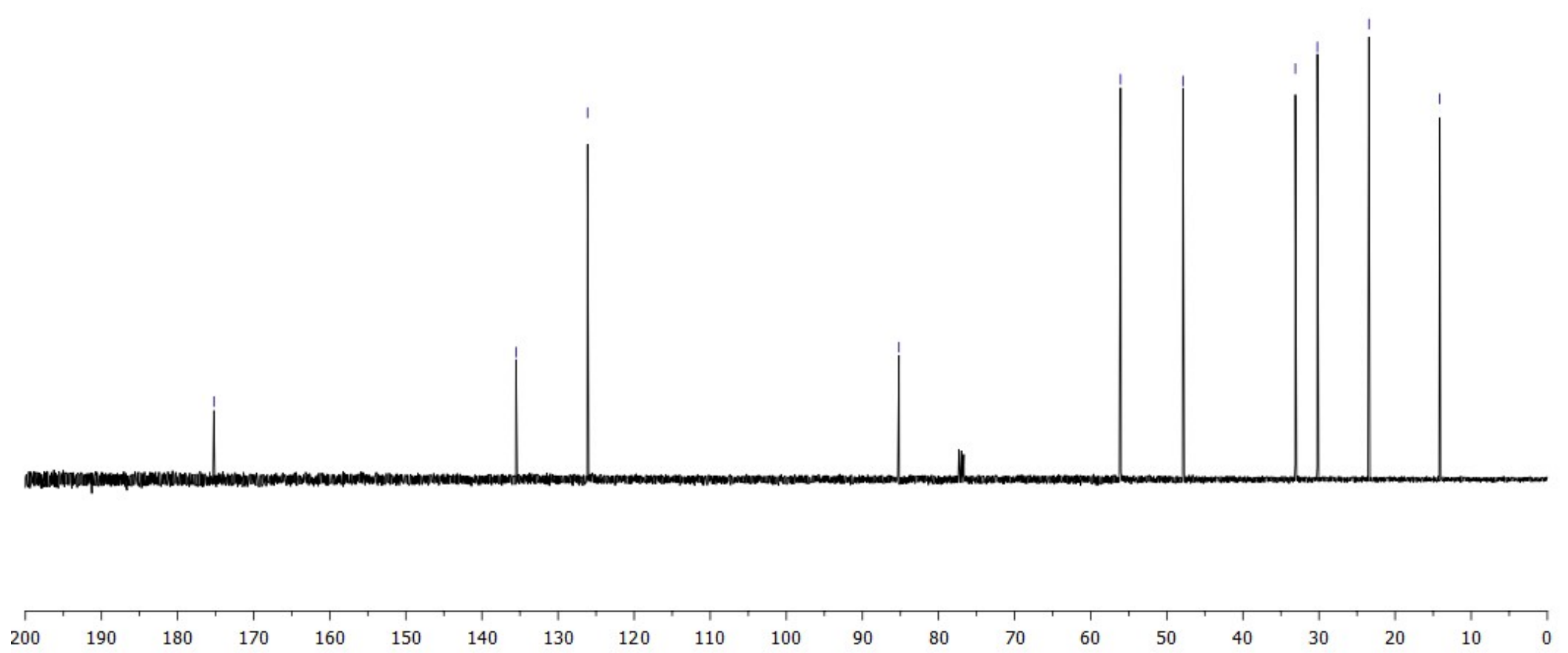


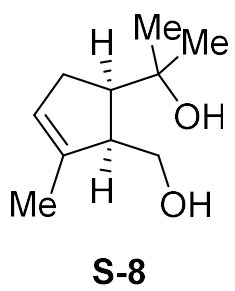

ๆ

पै।

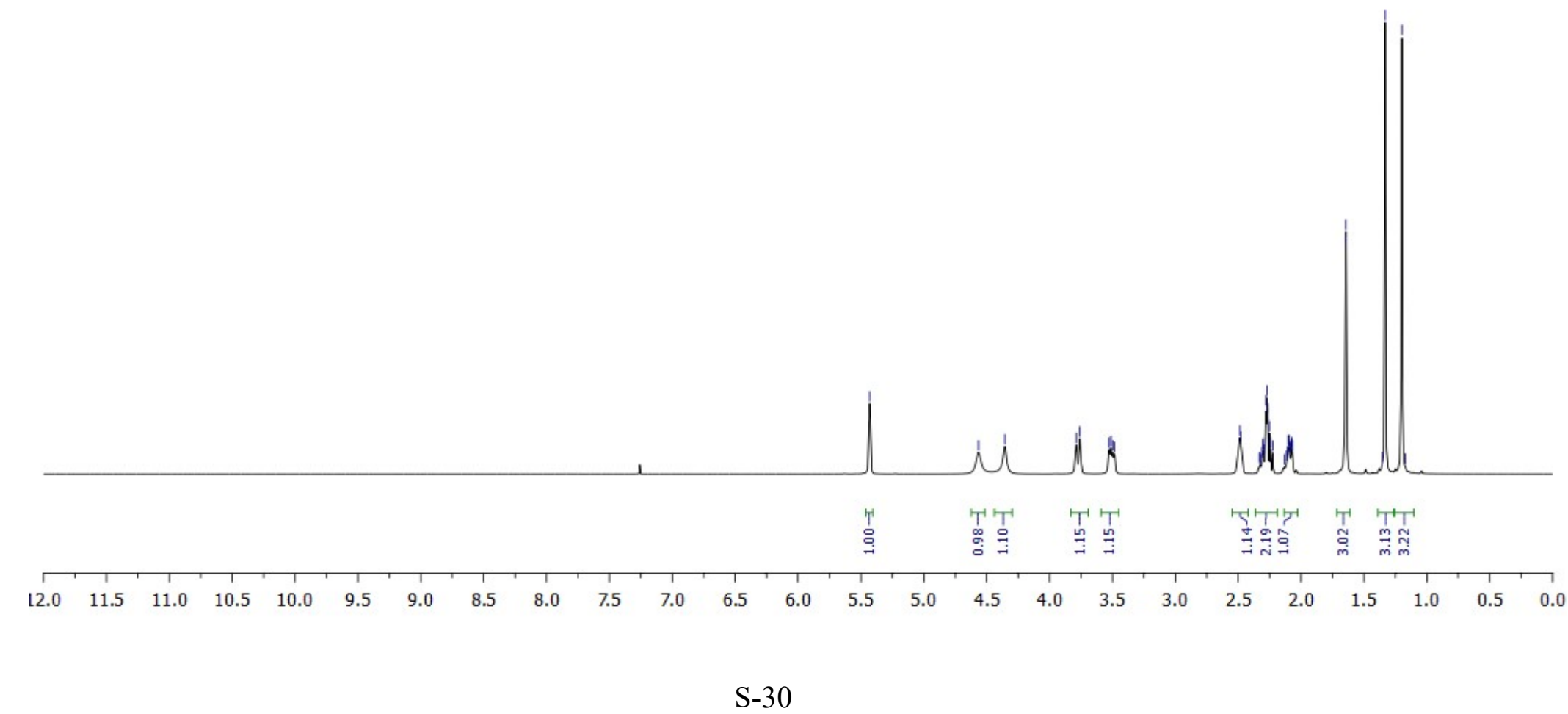



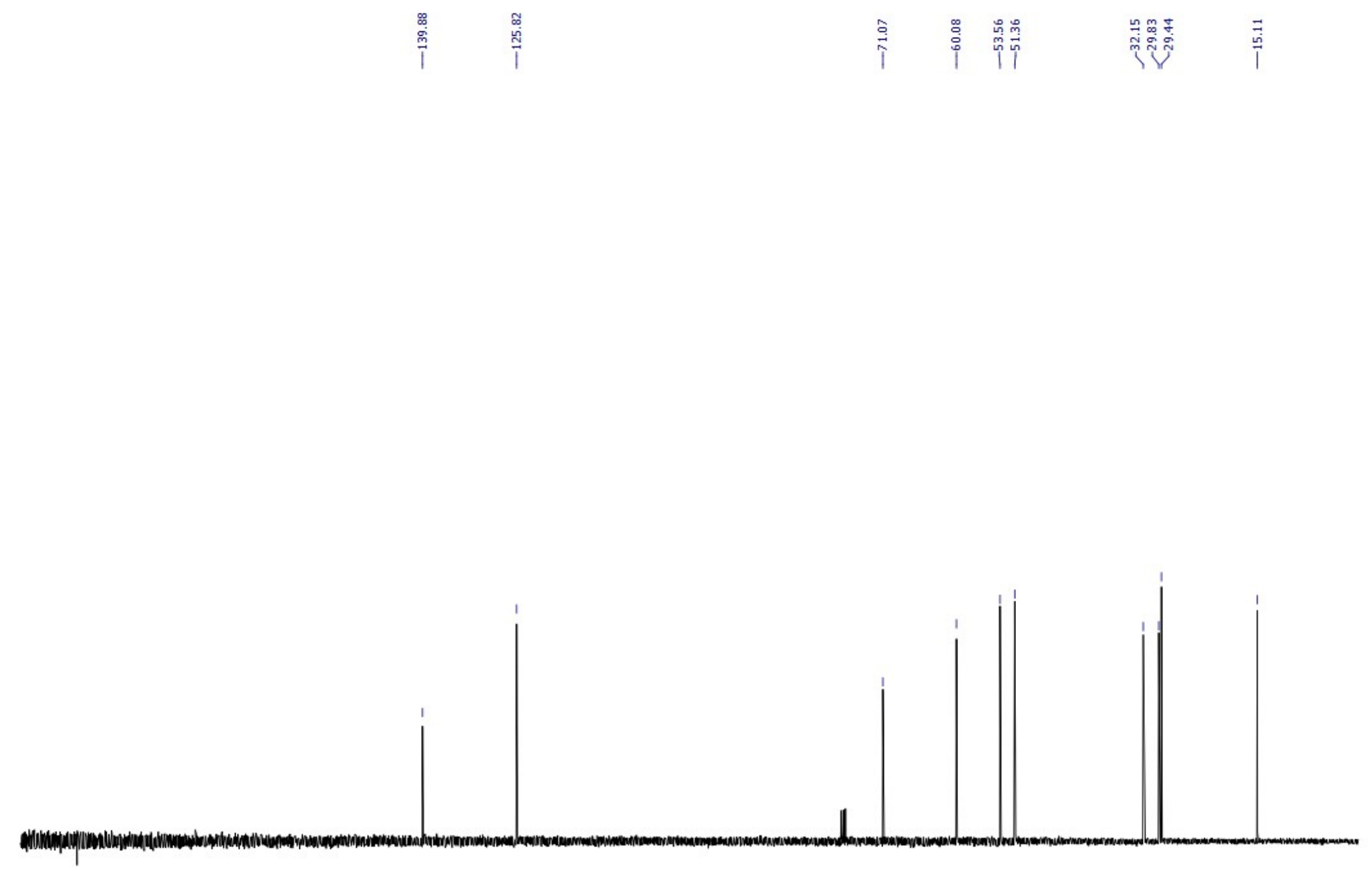

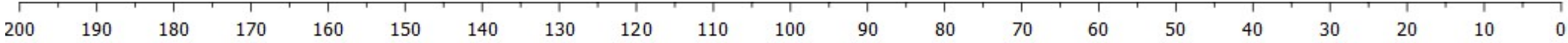




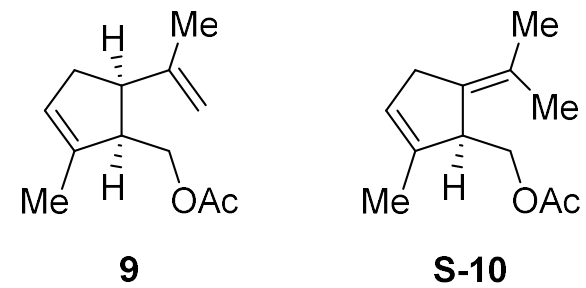

Vi

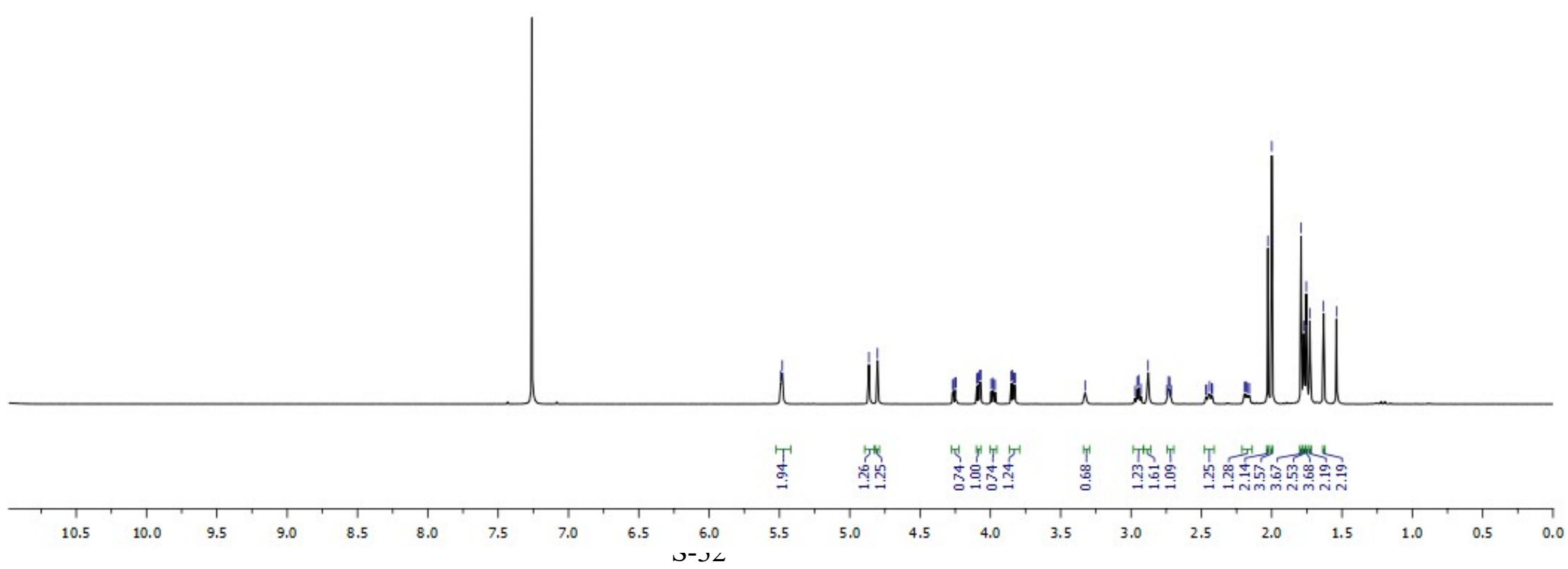



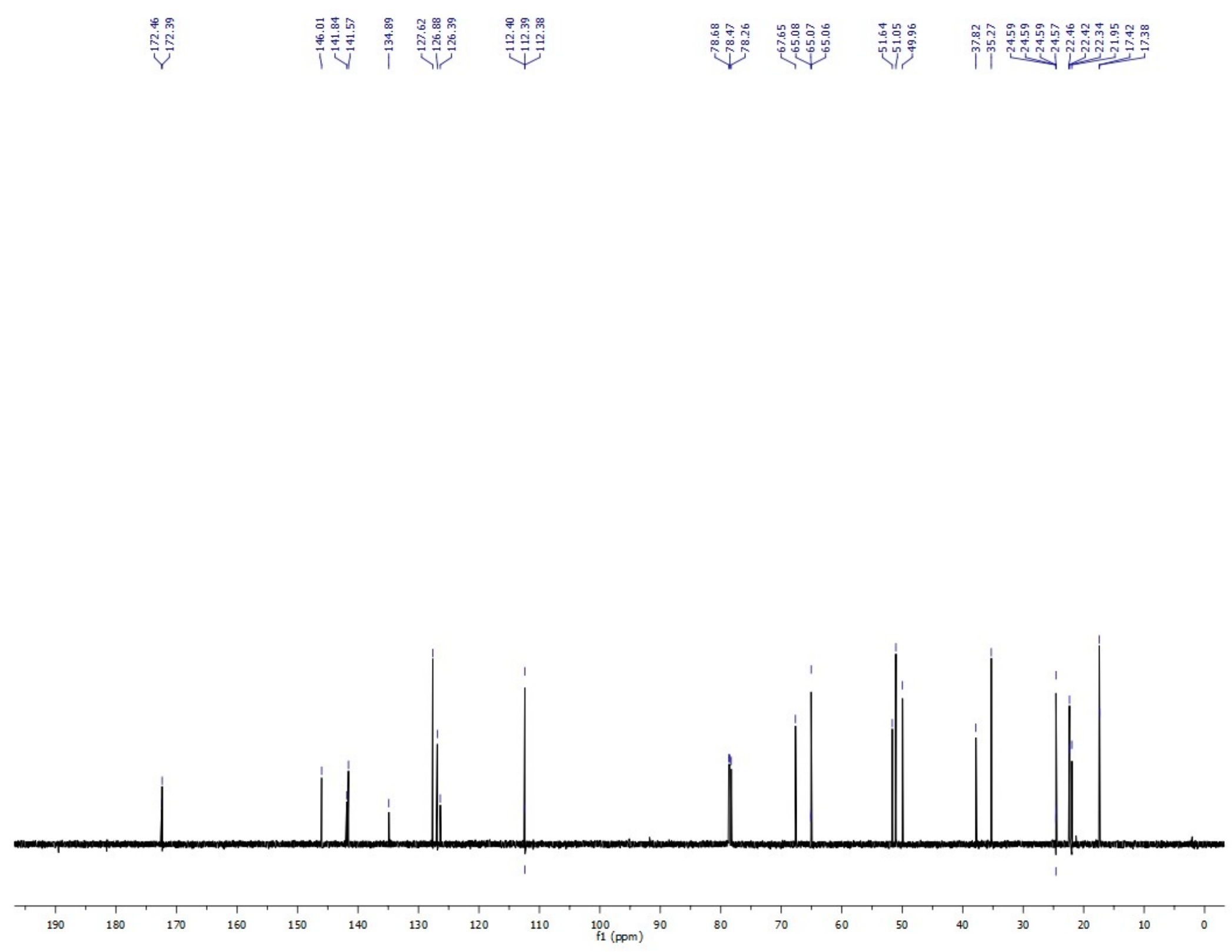

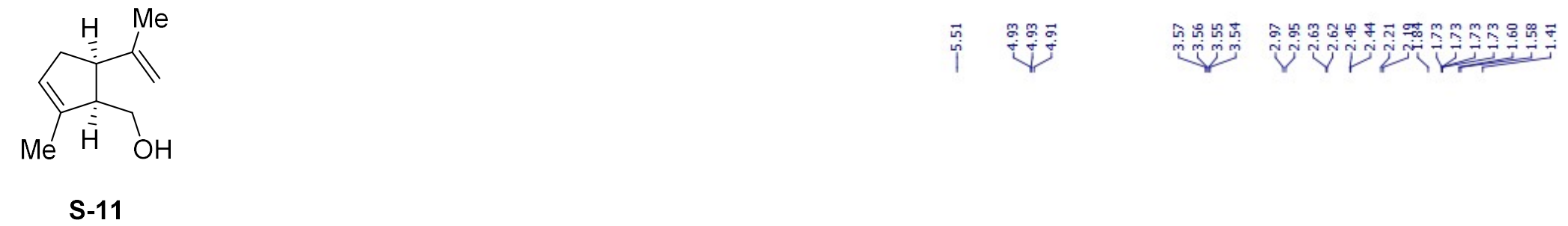

S-11

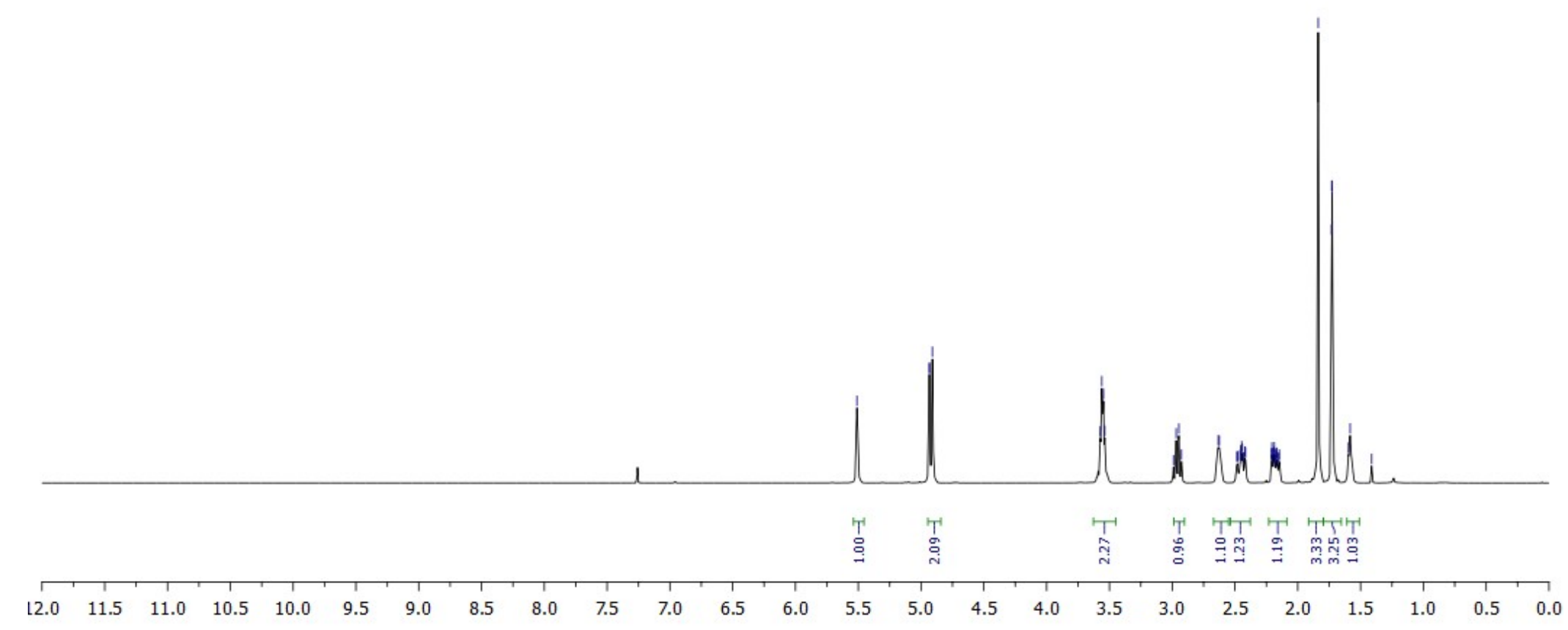




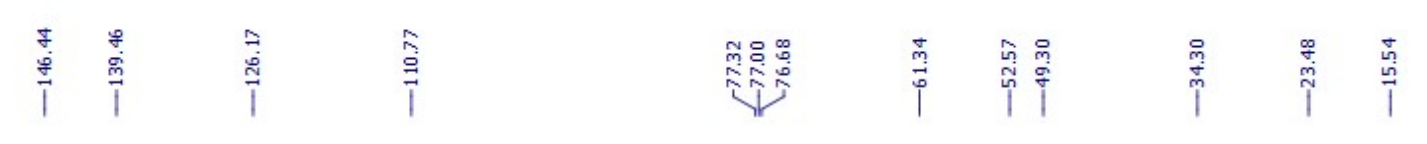
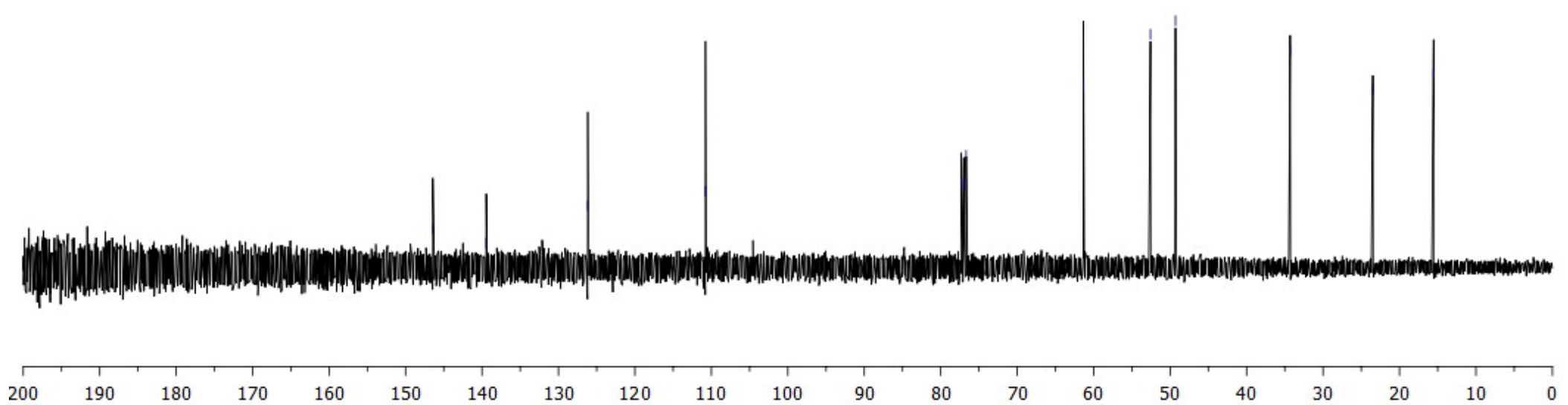

S-35 

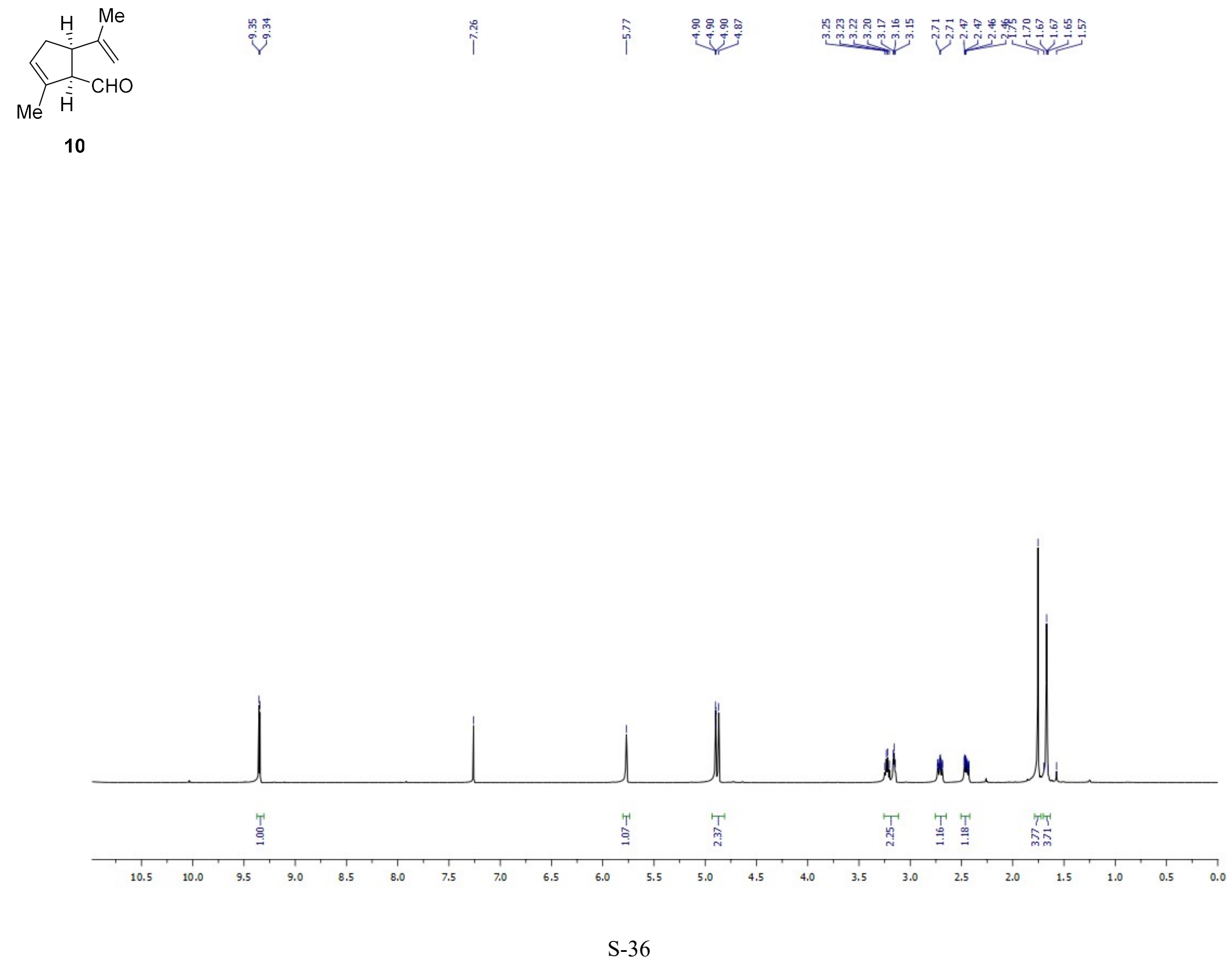



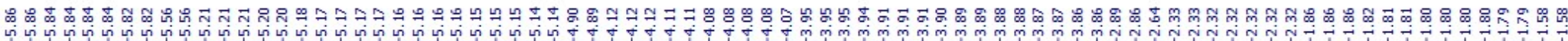

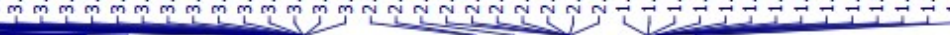

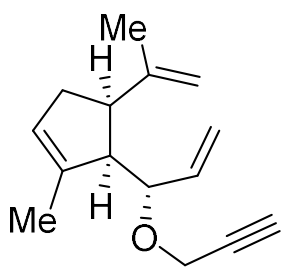

11

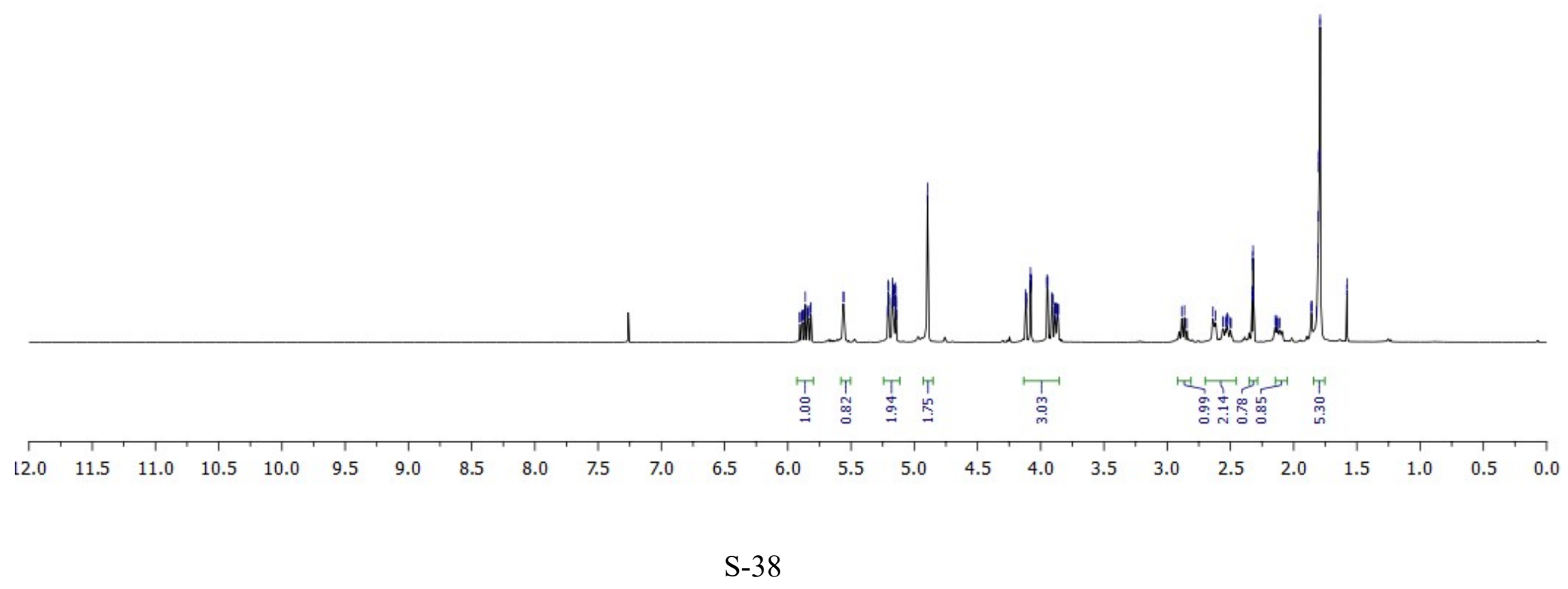




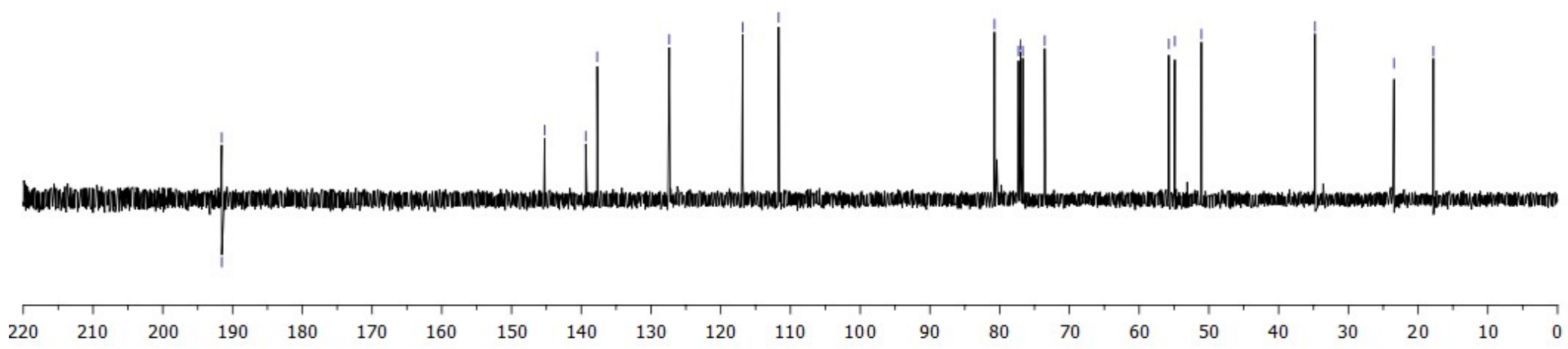




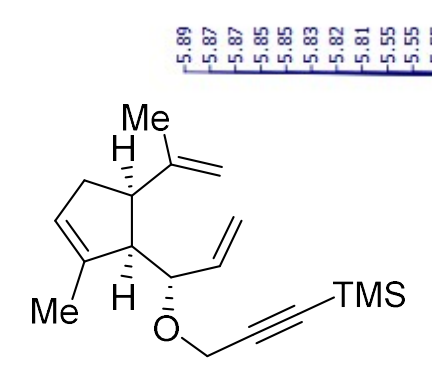

12

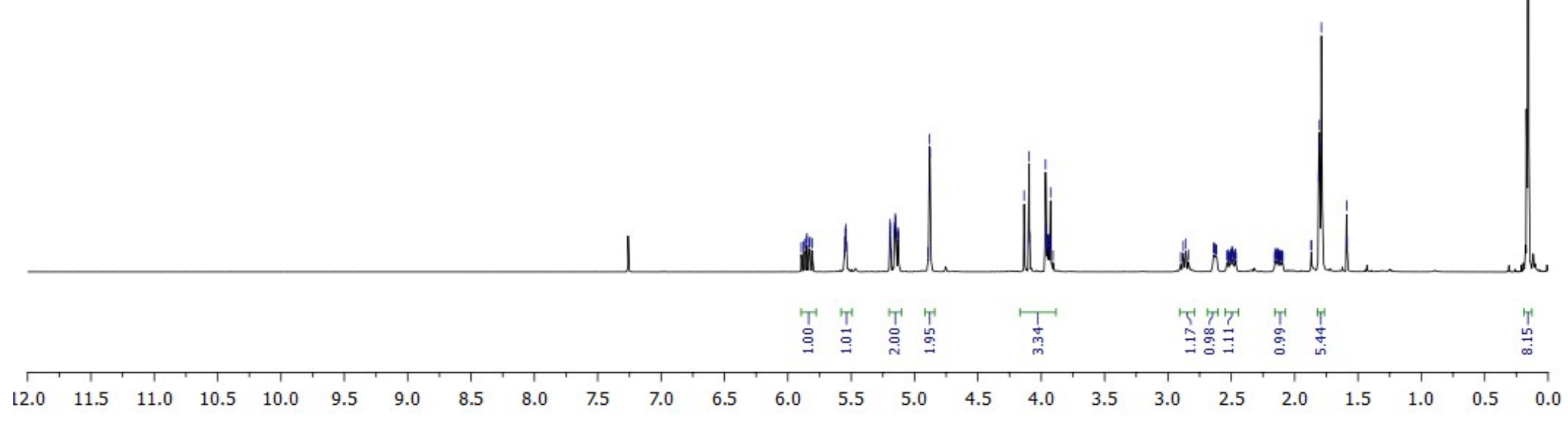




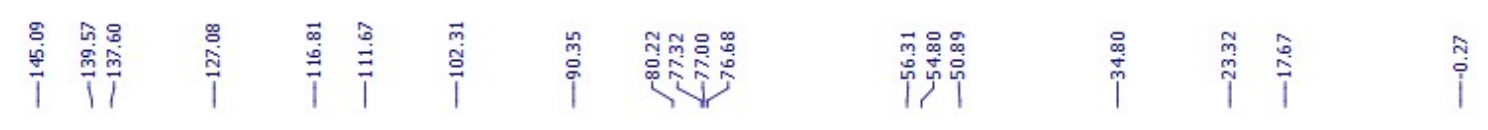

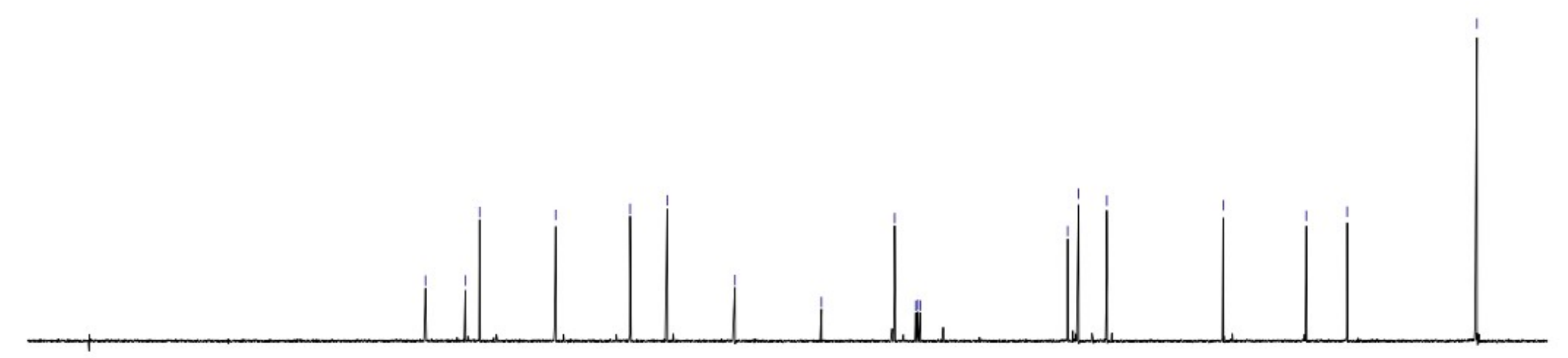

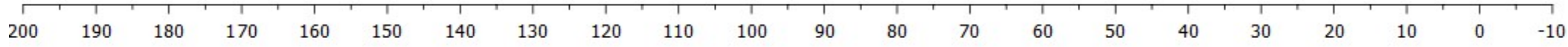




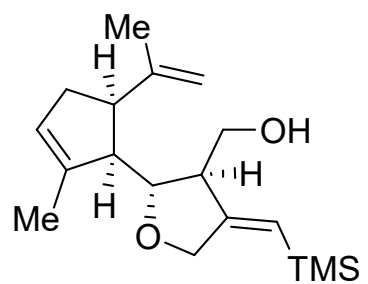

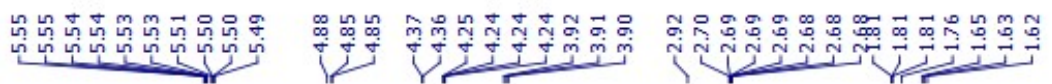

13

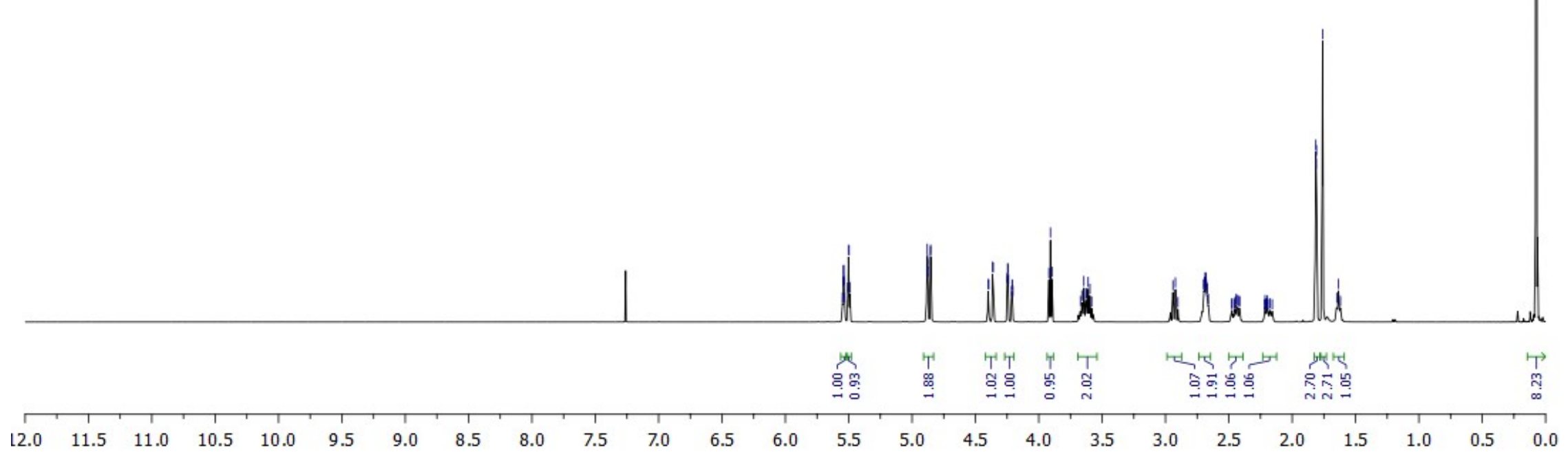




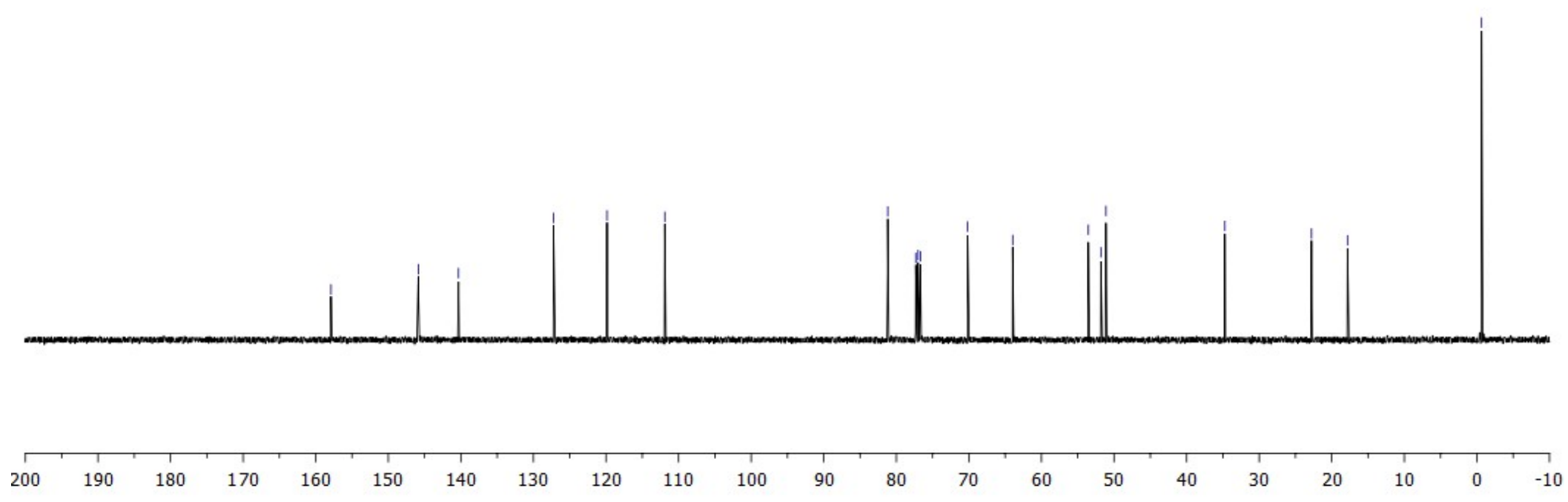




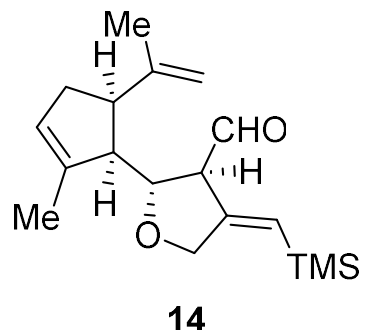

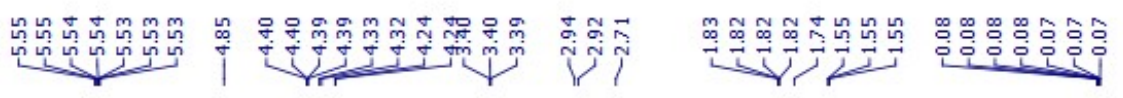

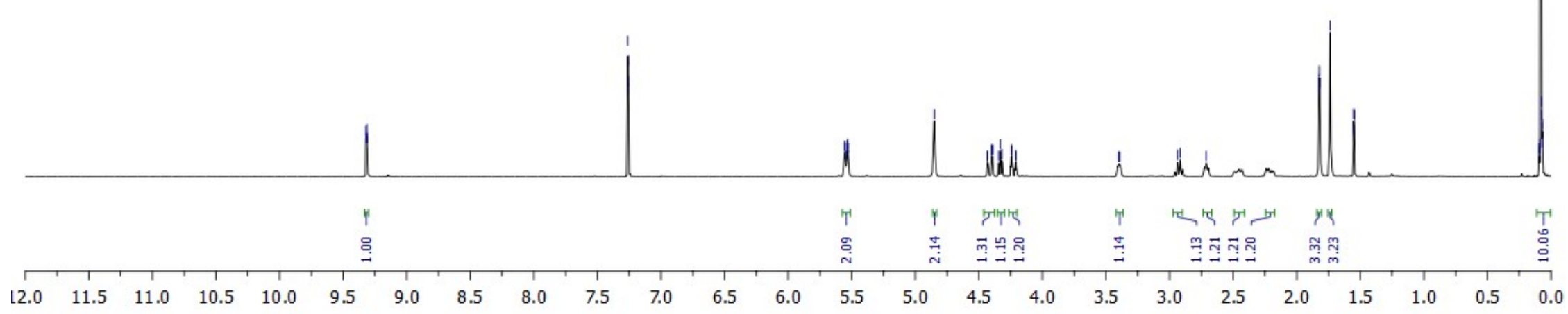




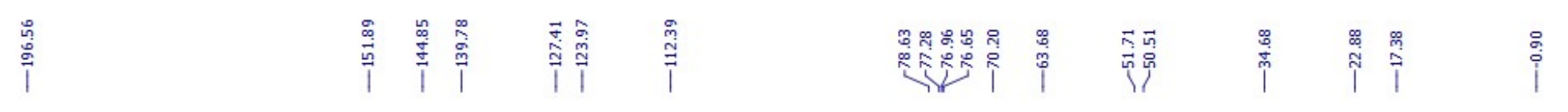
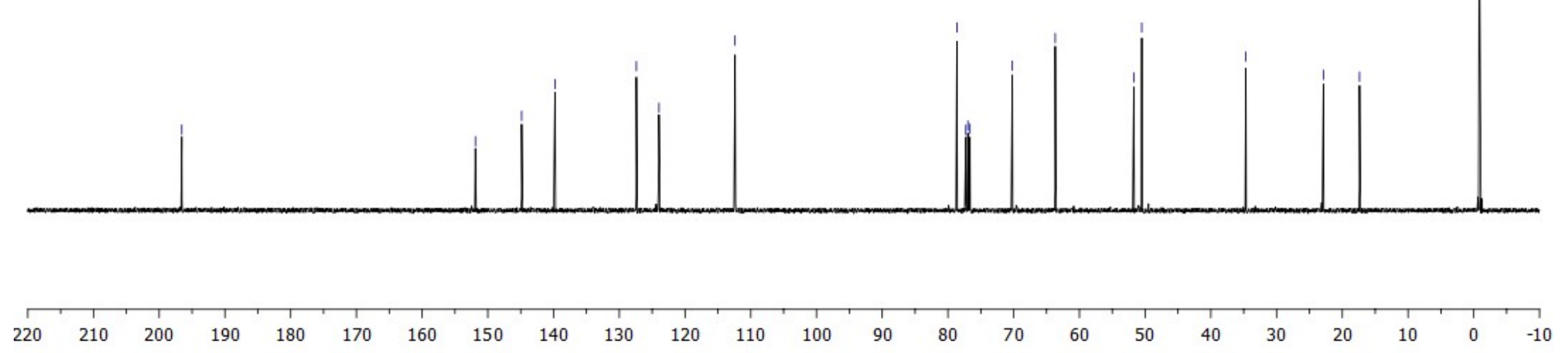


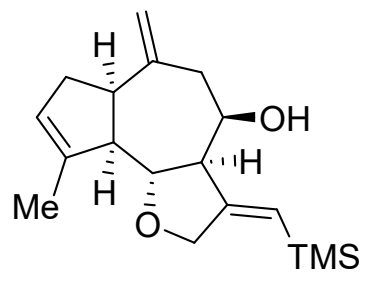

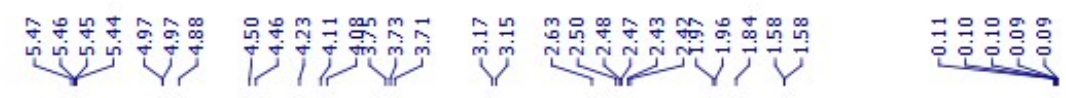

15

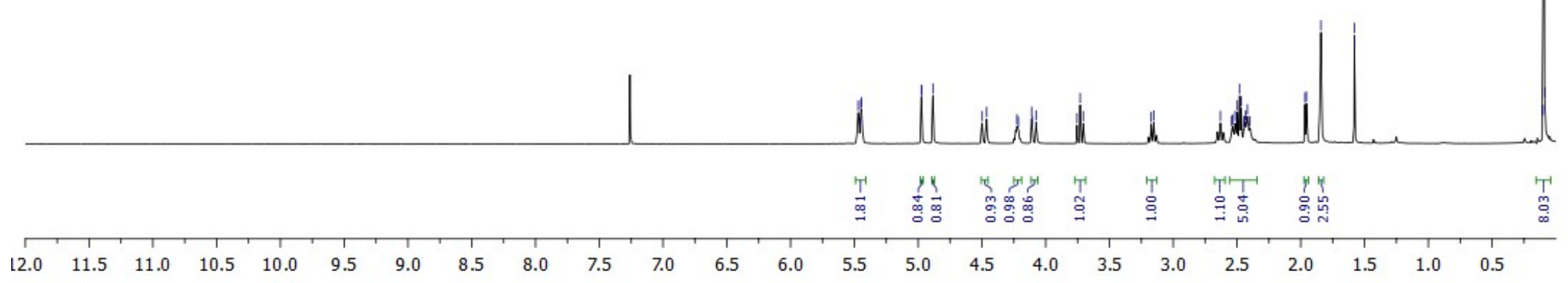

S-46 


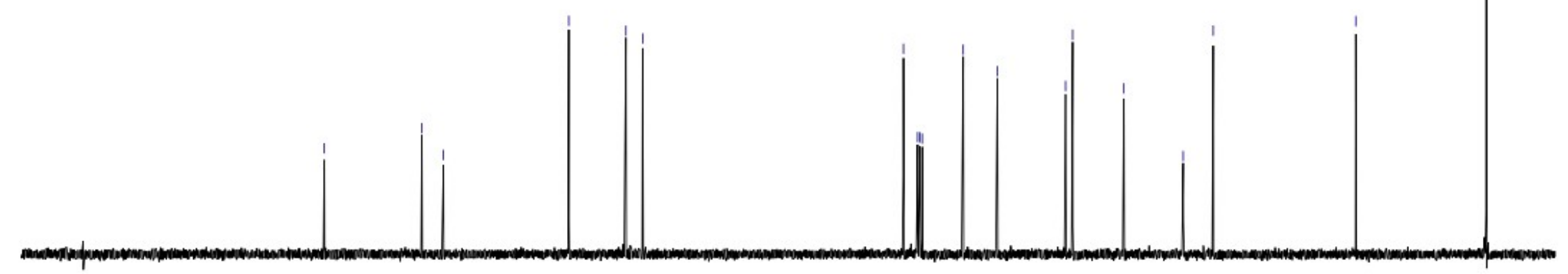

$$
200
$$



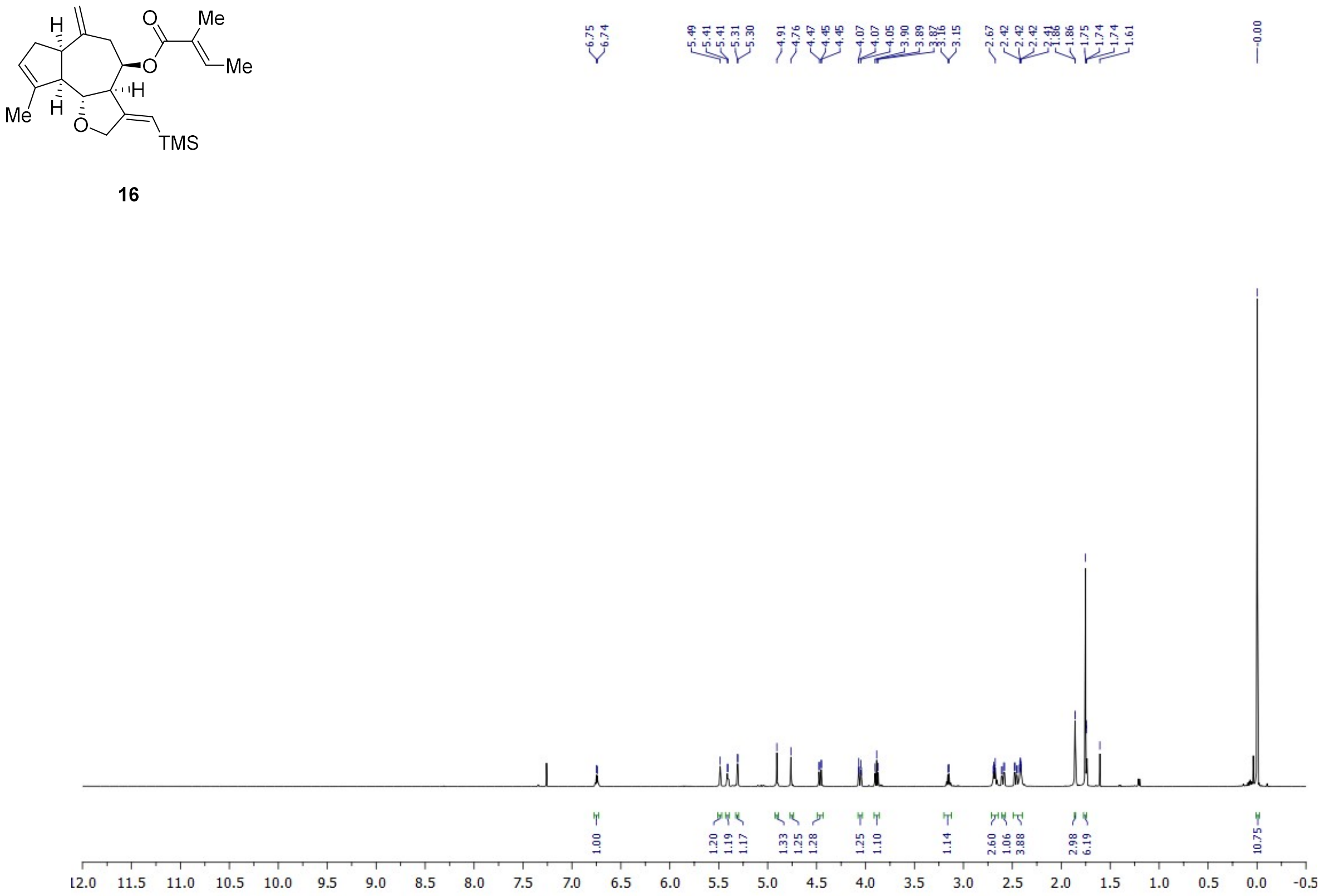


$$
\text { li }
$$

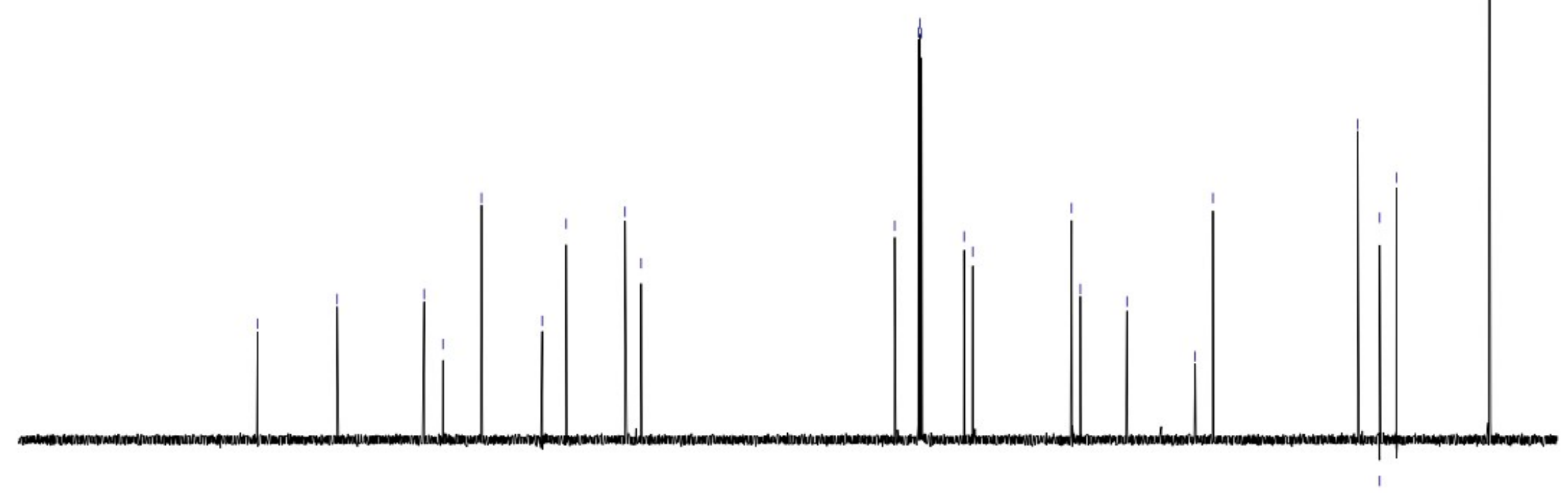

$$
200
$$




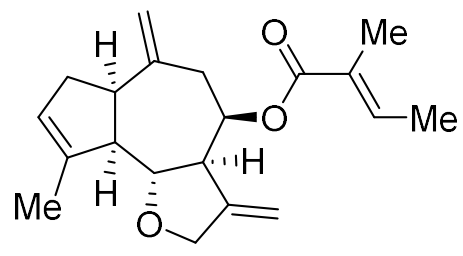

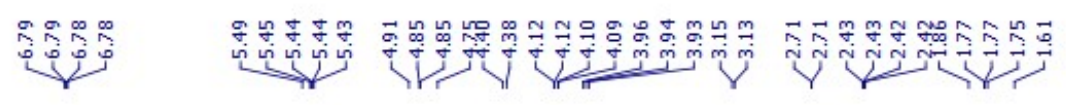

17

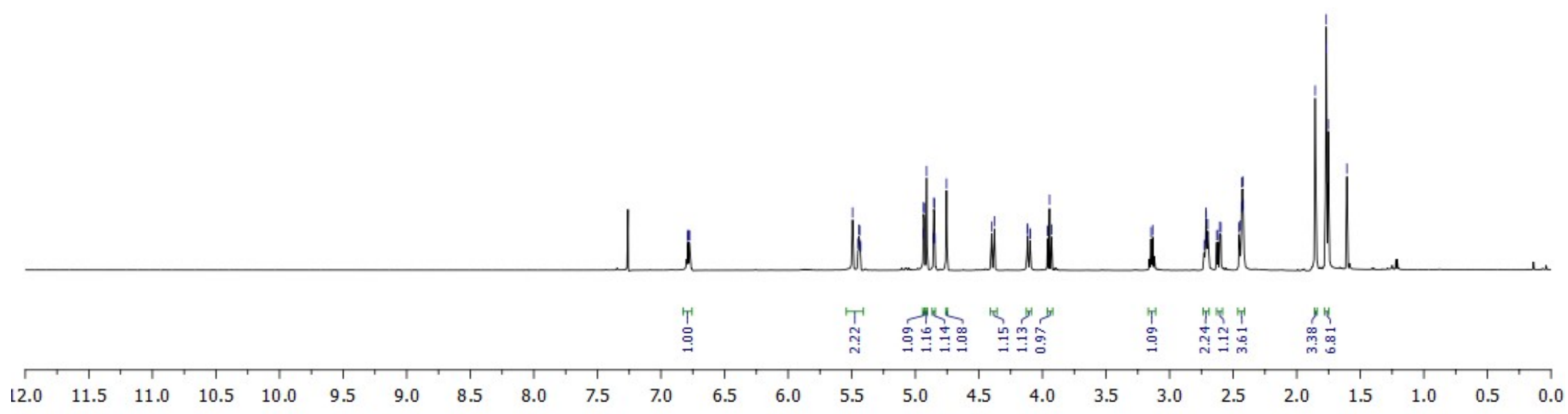




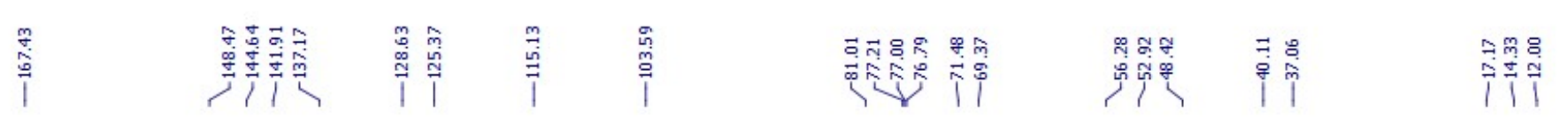
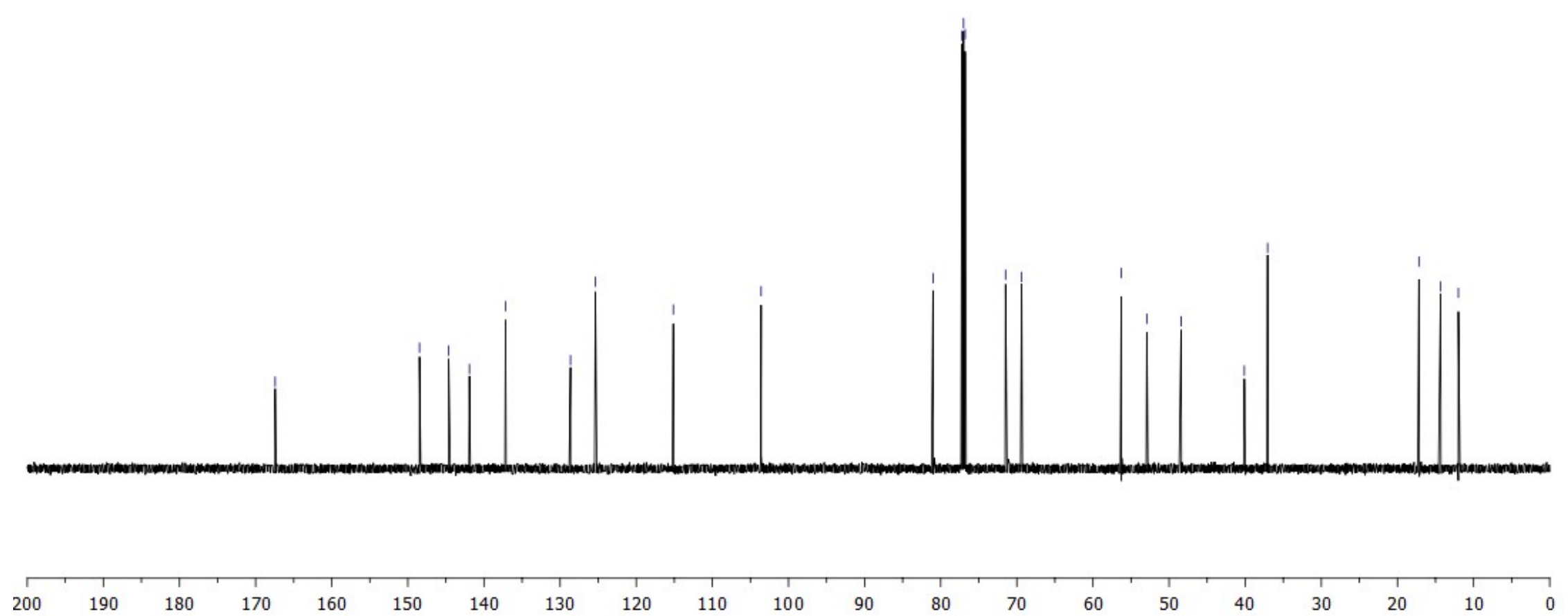


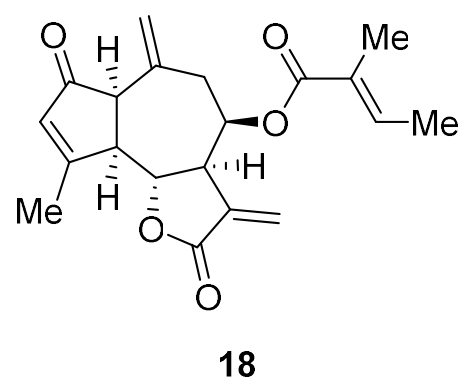

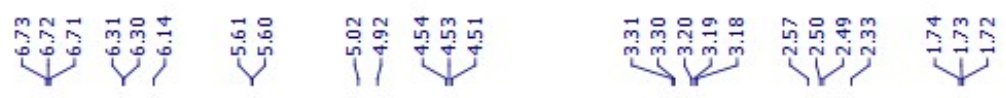

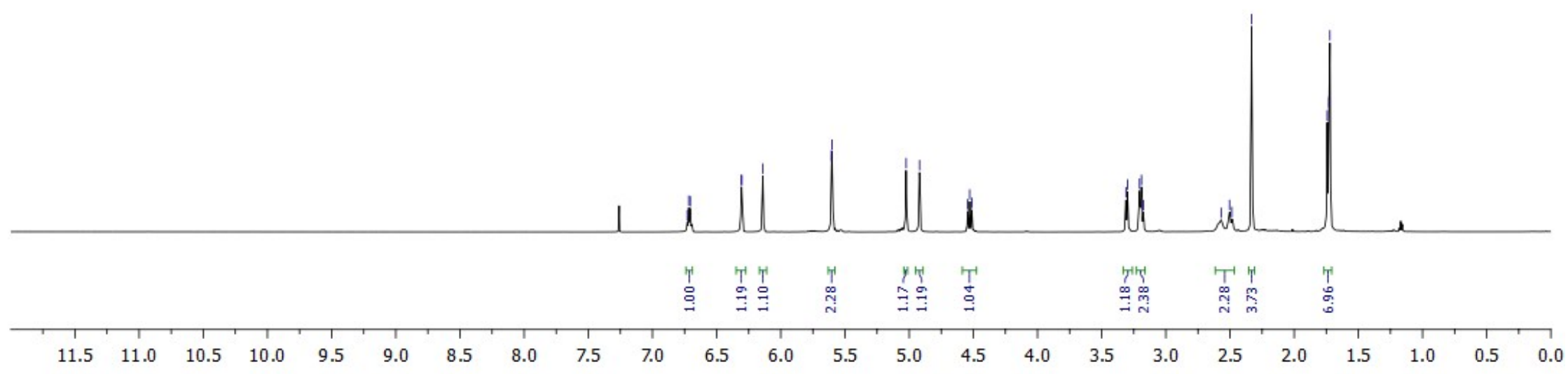



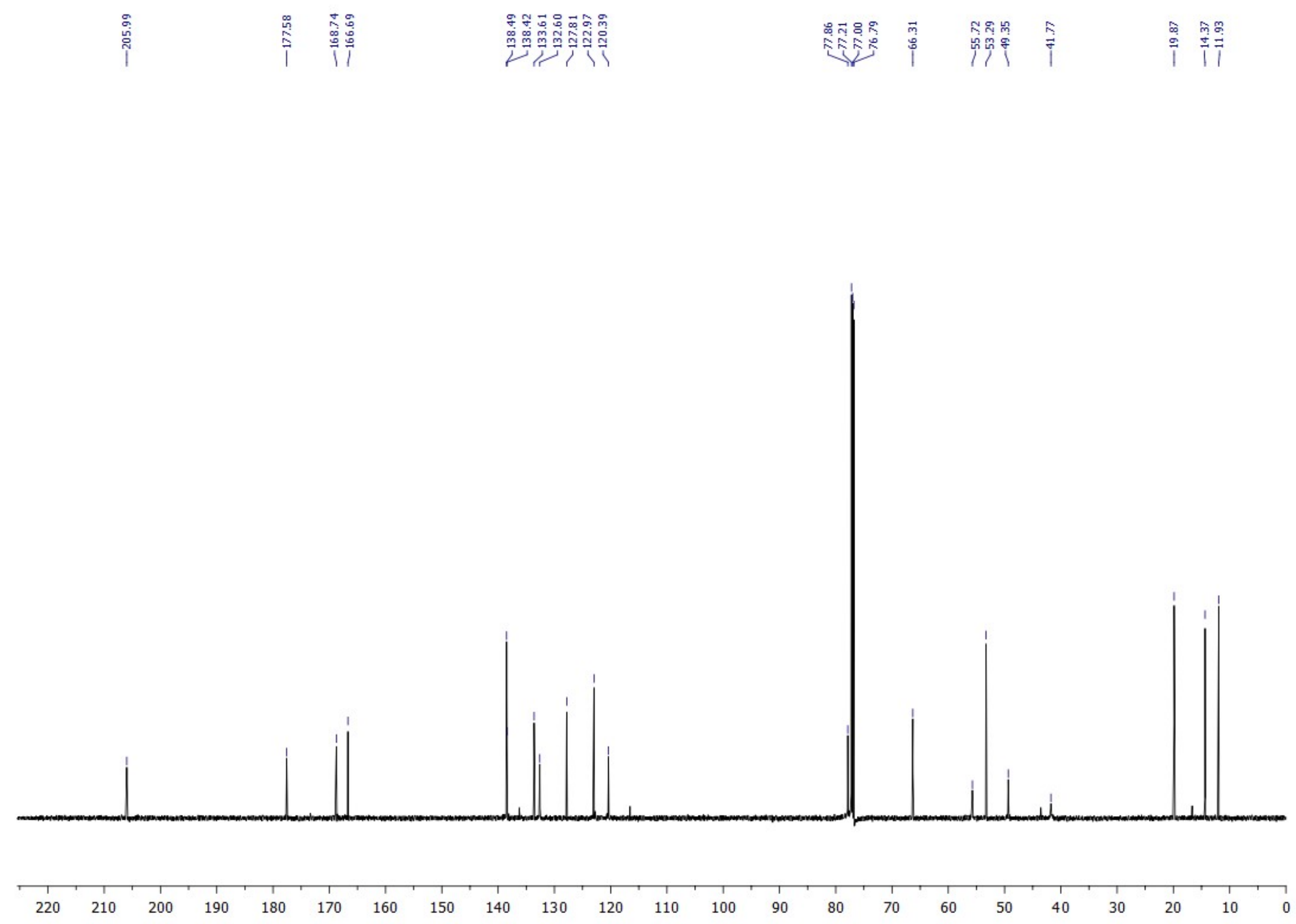

S-53 


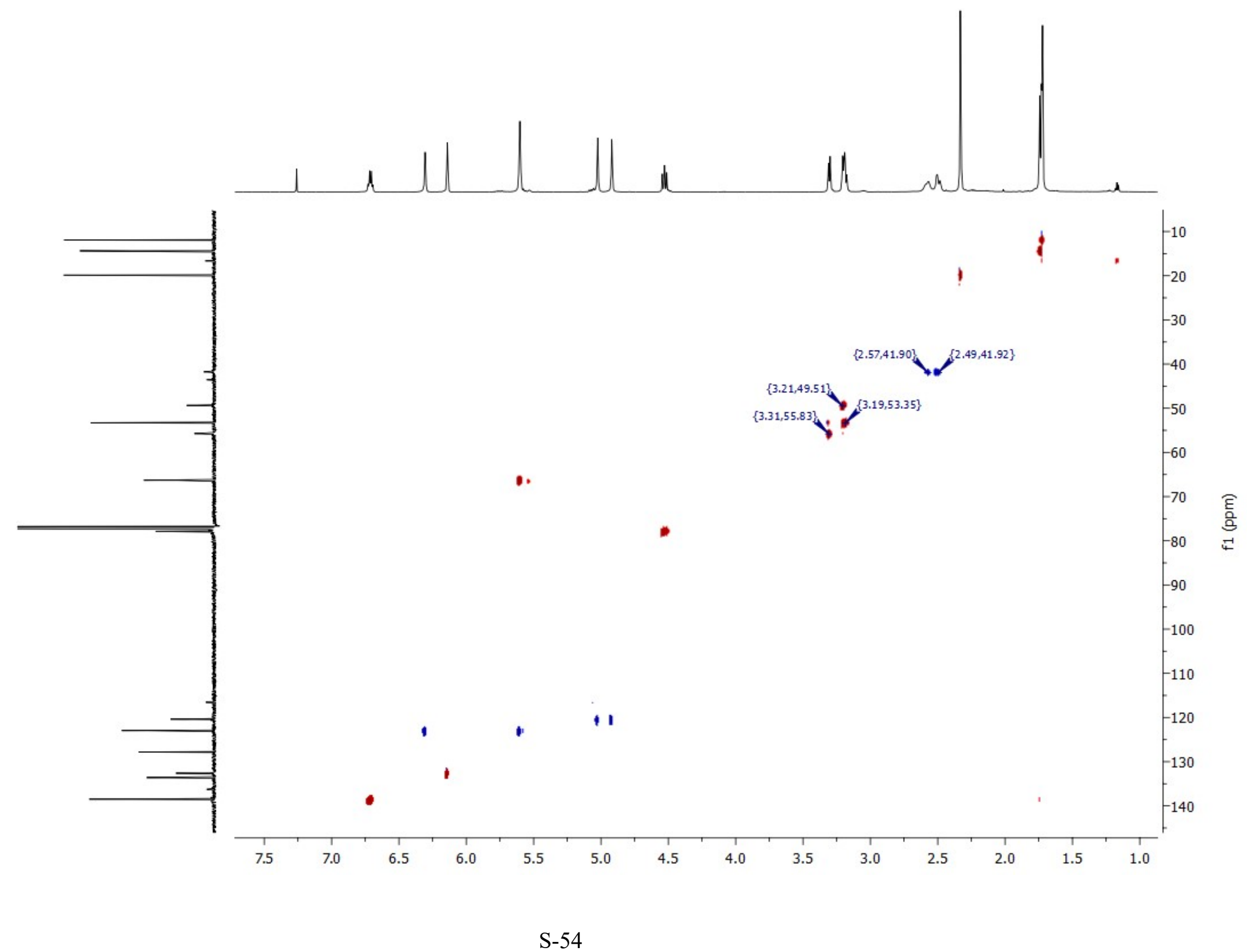




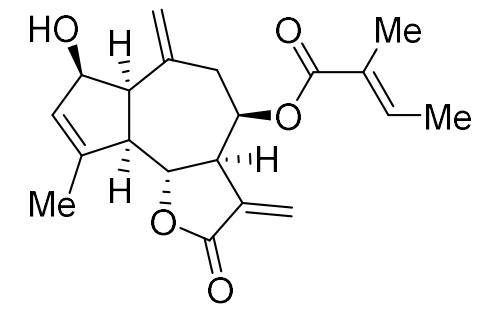

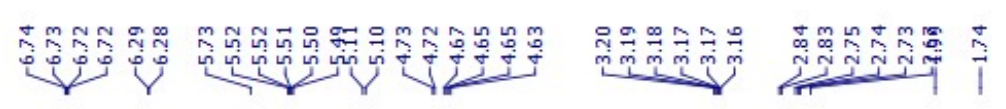

19

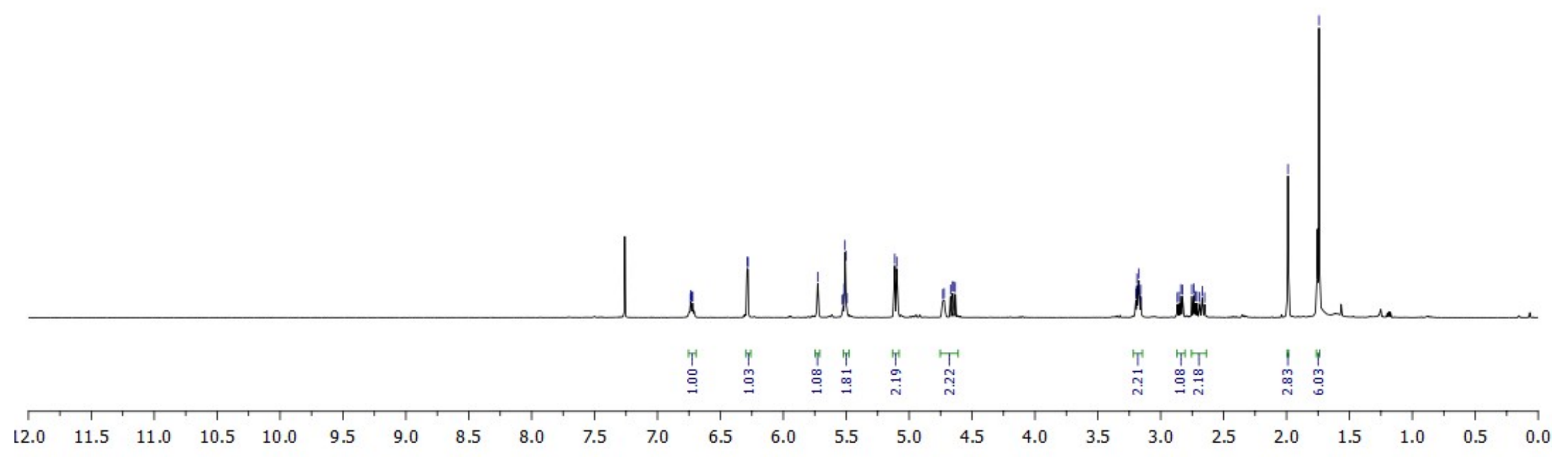




$$
\text { li }
$$



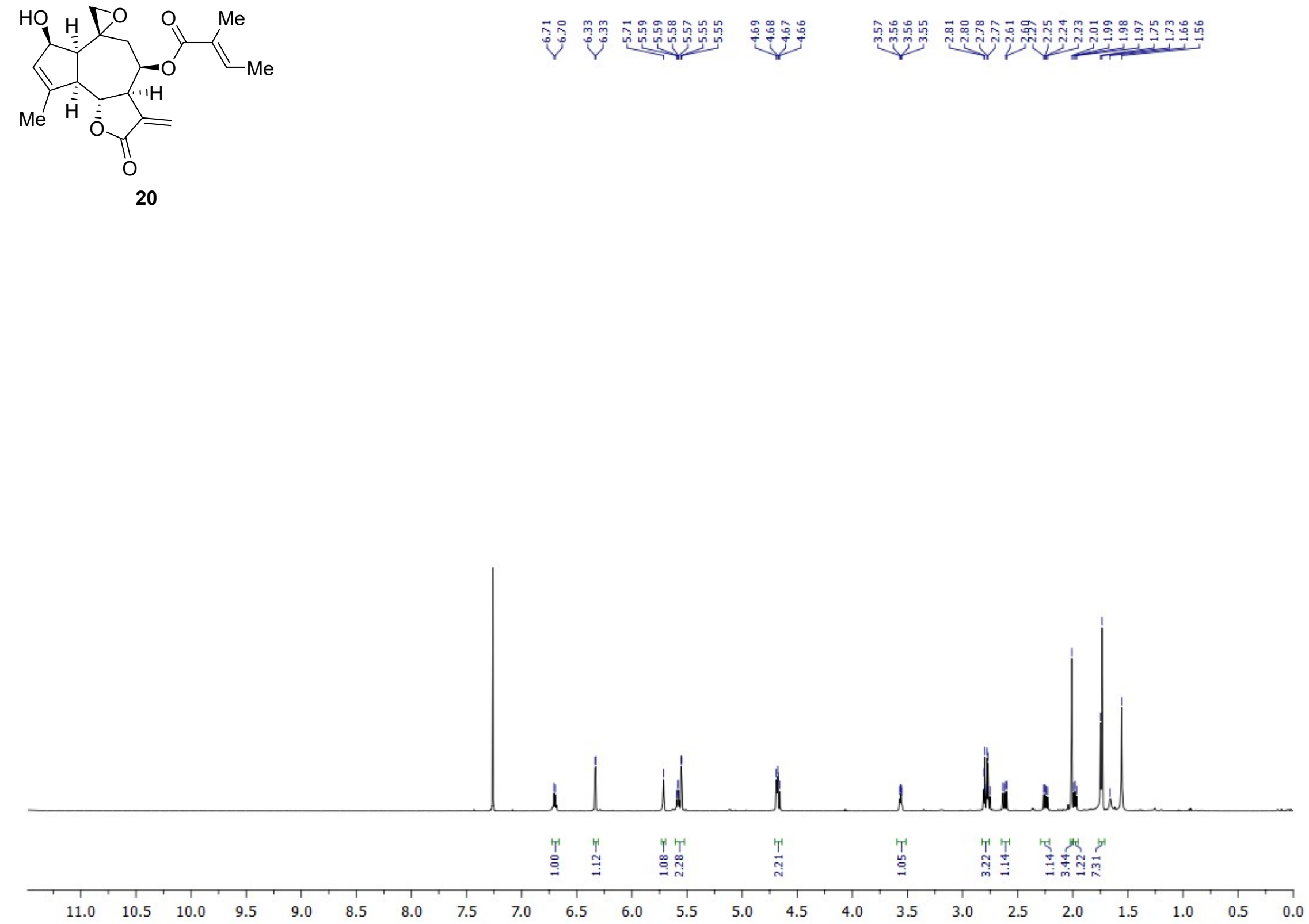


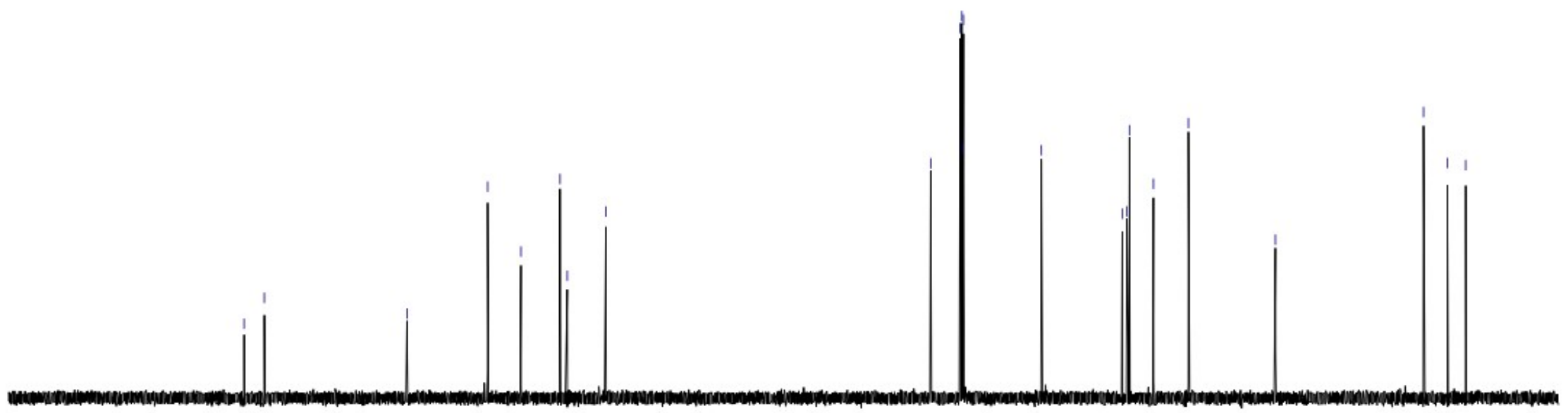




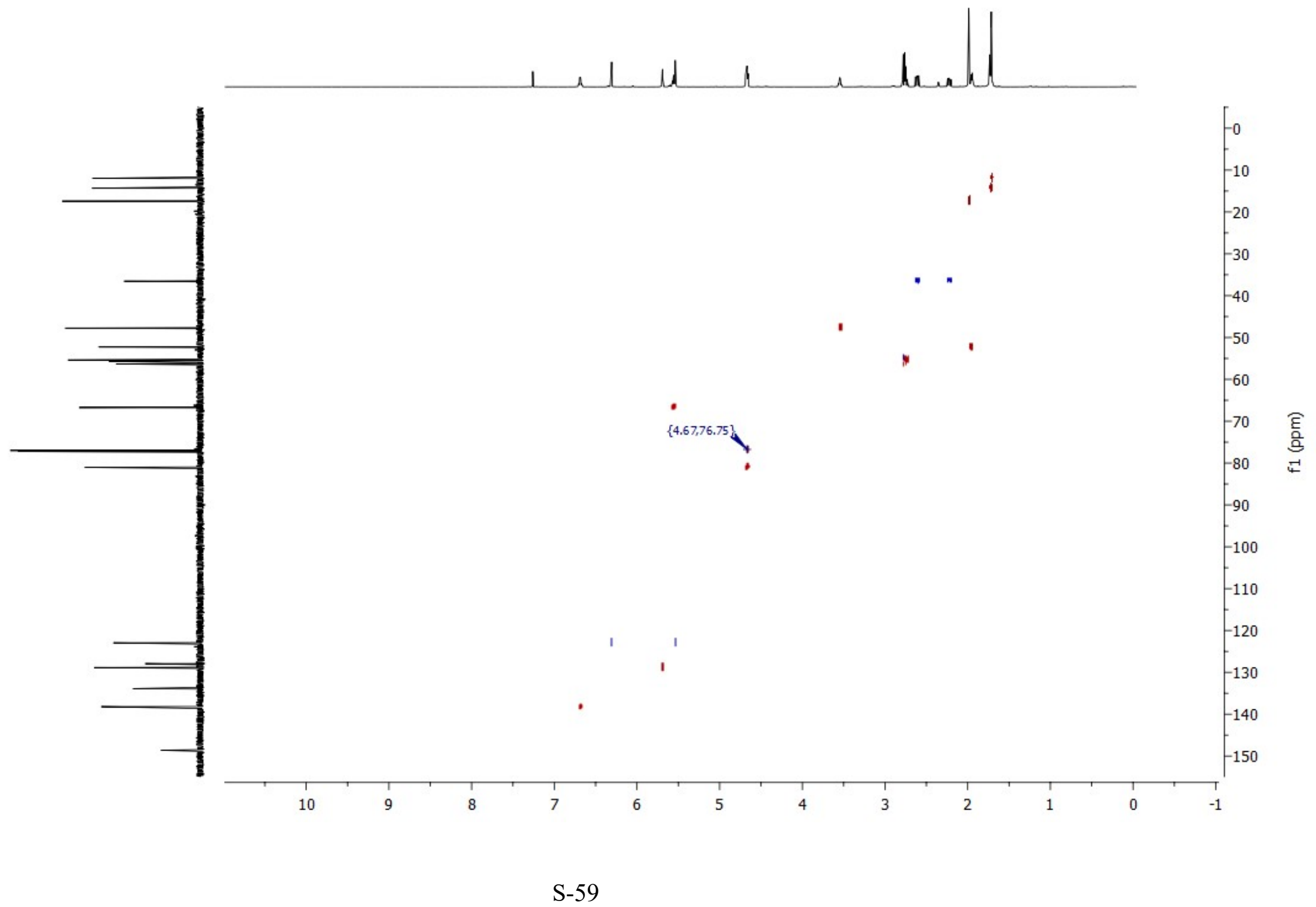



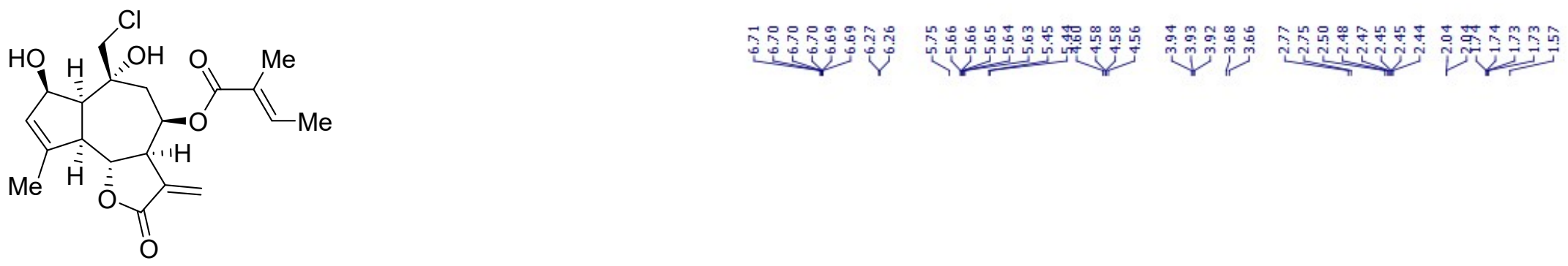

eupalinilide $E$ (1)

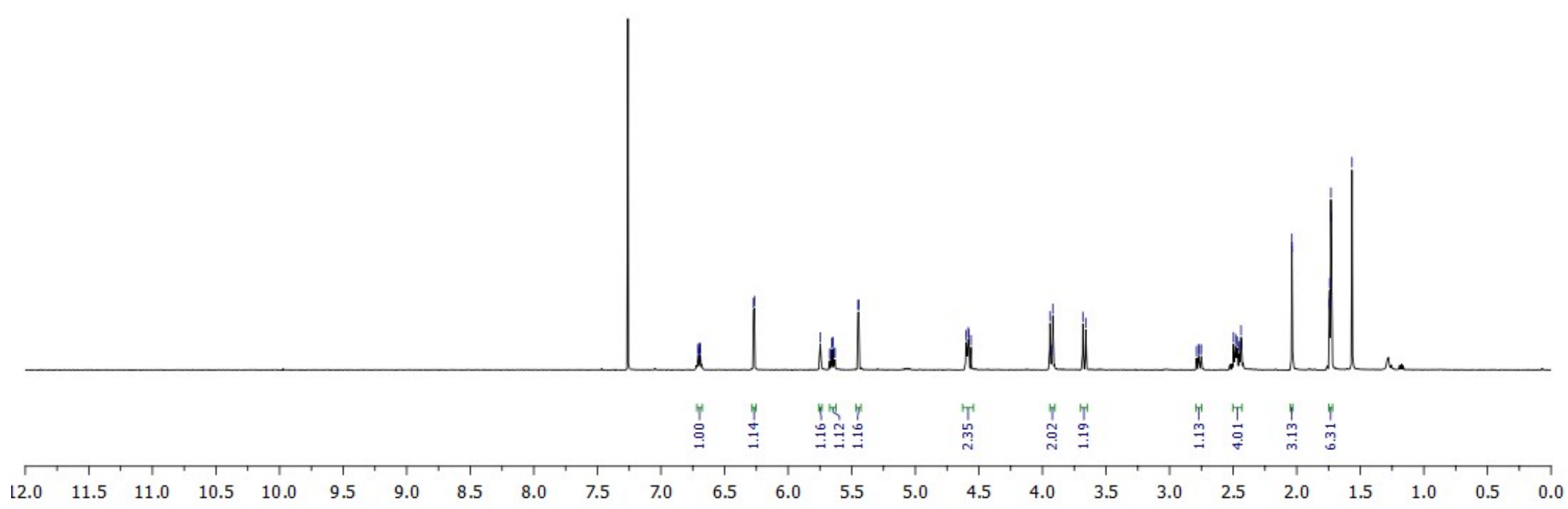




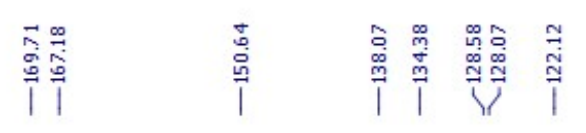

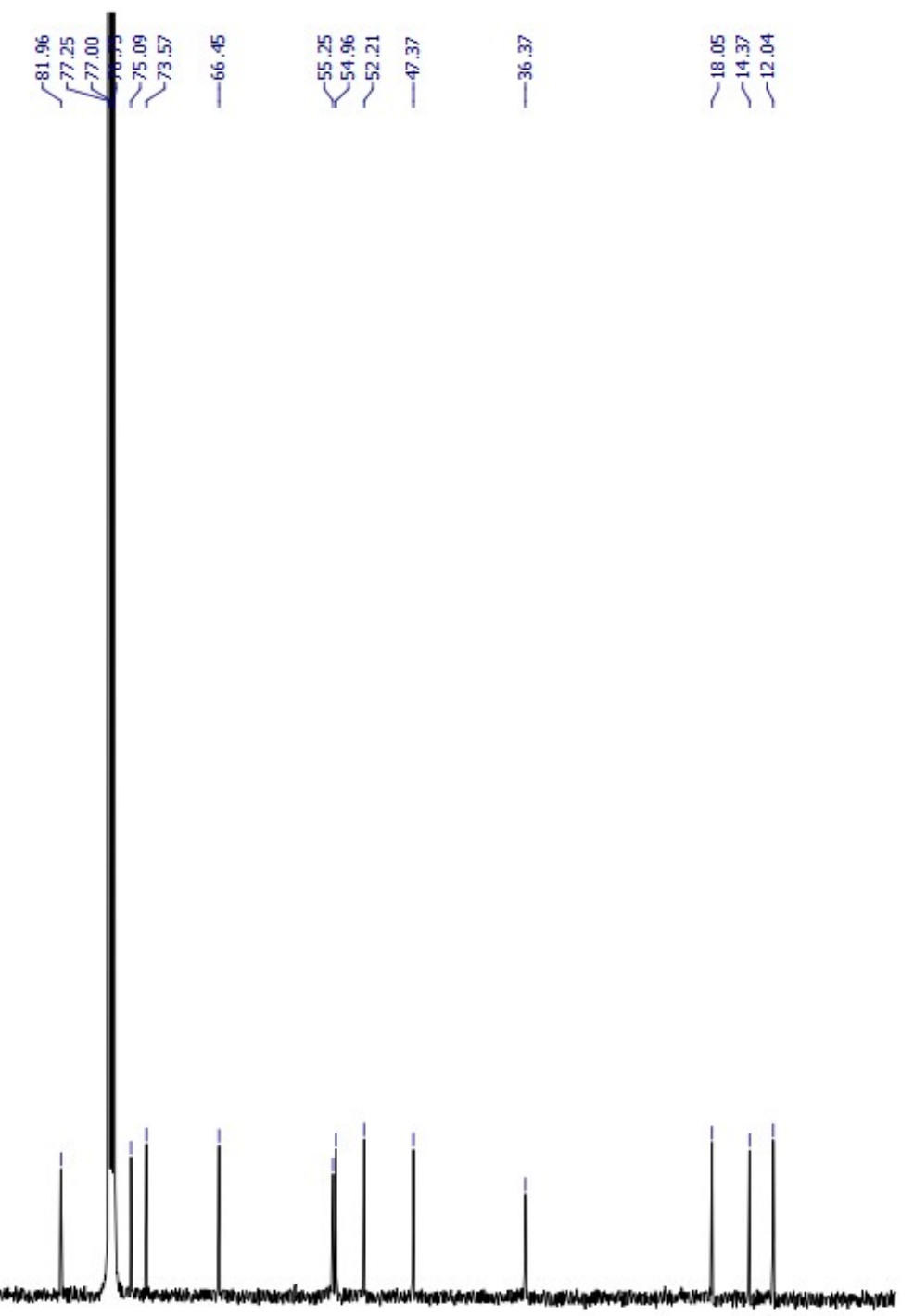

200

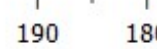

170

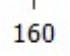


Clonogenic assays

Clonogenic assays were performed according to standard protocol[1]. Cells were counted using Scepter automated cell counter (Millipore) and 1000 cells were seeded per plate. A549 Cells were treated with eupalinilide E or DMSO solvent control. Canon Rebel T3i digital camera was used to create a digital image of each plate, number of colonies larger than cutoff threshold was scored using a custom Matlab script. Number of colonies per plates was normalized to number of colonies on plates treated only with DMSO solvent.

Franken NA, Rodermond HM, Stap J, Haveman J, van Bree C: Clonogenic assay of cells in vitro. Nat Protoc 2006, 1:2315-2319.

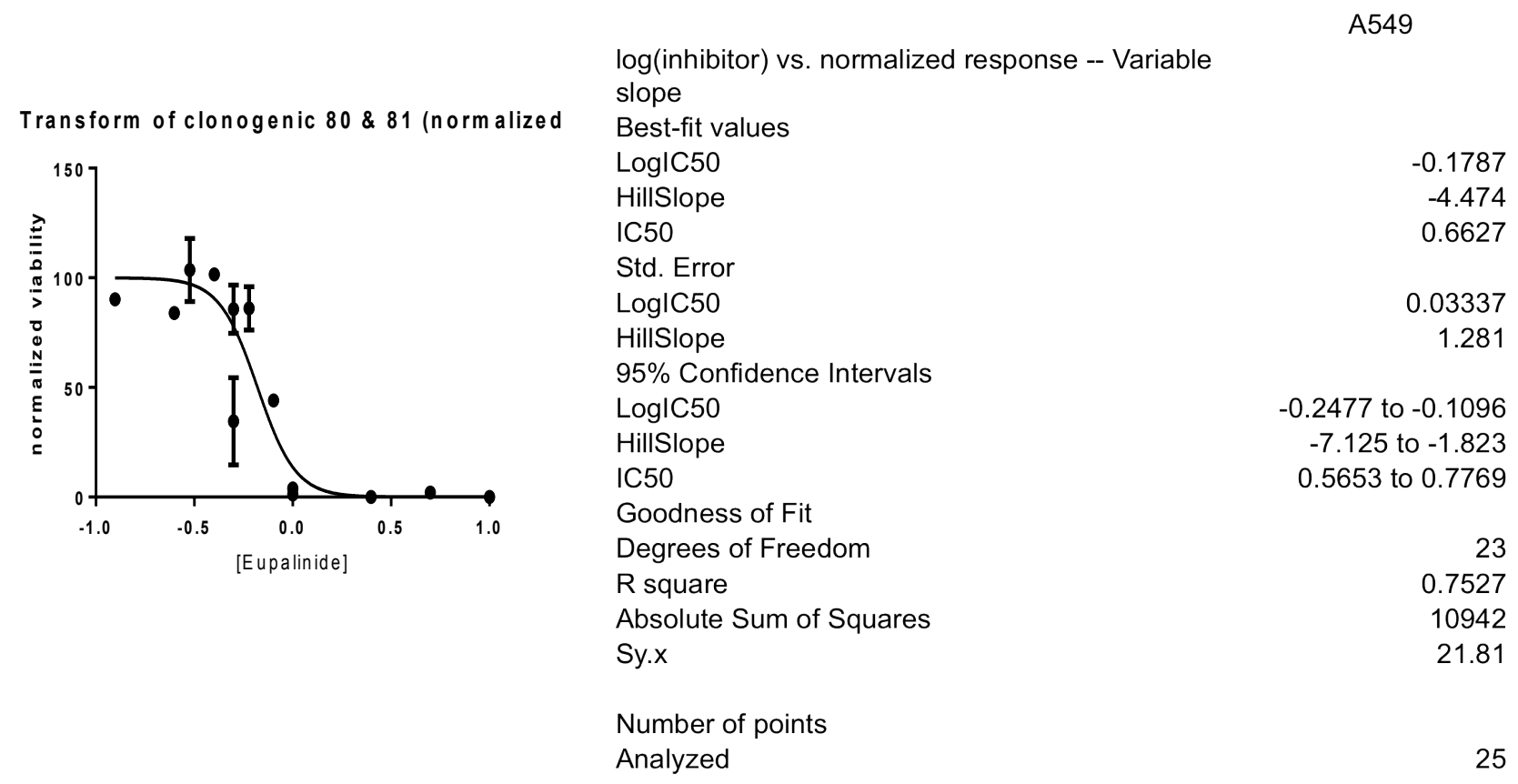


HSPC Expansion Methods:

CD34+ cell culture

CD34+ cord blood cells were purchased from Stemcell Technologies. The cells were quickly thawed according to the instructions and resupsended at $5 \times 10^{4}$ cells $/ \mathrm{mL}$ in HSC expansion medium (StemSpan SFEM [Stemcell Technoligies] supplemented with $1 \times$ antibiotics and $100 \mathrm{ng} / \mathrm{mL}$ of recombinant human cytokines: stem cell factor ([hSCF], thrombopoietin [hTPO], Flt3 ligand [Flt3L], interleukin-6 [hIL6] [Peprotech]). The DMSO or eupalinilide $\mathrm{E}$ at various dosages were added immediately to the HSPC expansion medium after plating the cells. The cells were replated at $5 \times 10^{5}$ cells $/ \mathrm{mL}$, as needed. The live cells were counted with Trypan blue staining.

\section{Flow cytometry analysis}

CD34+ cells were spin collected to remove medium and resuspended in staining medium (PBS upplemented $0.5 \%$ BSA and 2mM EDTA). The cells were stained with APC conjugated anti-human CD34 antibody (eBioscience) for 1 hour at $4^{\circ} \mathrm{C}$. The cells were then washed and resuspended in staining medium. The flow cytometry analysis was performed on FACSCanto (BD Bioscience). UltraComp eBeads (eBioscience) was used for single staining control. The flow cytometry FCS data was further analyzed in Flowjo software. 